This item was submitted to Loughborough's Research Repository by the author.

Items in Figshare are protected by copyright, with all rights reserved, unless otherwise indicated.

\title{
An investigation of tin whisker growth over a 32 year period
}

\section{PLEASE CITE THE PUBLISHED VERSION}

http://dx.doi.org/10.1108/CW-07-2015-0038

\section{PUBLISHER}

(C) Emerald

\section{VERSION}

AM (Accepted Manuscript)

\section{PUBLISHER STATEMENT}

This work is made available according to the conditions of the Creative Commons Attribution-NonCommercialNoDerivatives 4.0 International (CC BY-NC-ND 4.0) licence. Full details of this licence are available at: https://creativecommons.org/licenses/by-nc-nd/4.0/

\section{LICENCE}

CC BY-NC-ND 4.0

\section{REPOSITORY RECORD}

Ashworth, Mark, and B. Dunn. 2016. "An Investigation of Tin Whisker Growth over a 32 Year Period". figshare. https://hdl.handle.net/2134/22137. 


\begin{abstract}
Purpose: This paper presents the results of a 32 year old laboratory study of whisker growth from tin electrodeposits that was originally undertaken to gain an increased understanding of the phenomenon of tin whisker growth.

Design/methodology/approach: Whisker growth was evaluated using electroplated C-rings (both stressed and un-stressed) that were stored throughout in a desiccator at room temperature. Analysis has recently been undertaken to evaluate whisker growth and intermetallic growth after 32 years storage. SEM analysis has been performed to investigate whisker length and, using polished cross-sections, the morphology, thickness and type of intermetallic formation.
\end{abstract}

Findings: Normal tin plated deposits on brass and steel with a copper barrier layer nucleated whiskers within 5 months and in each case these grew to lengths between 1 and $4.5 \mathrm{~mm}$. For normal tin electroplated onto brass, a one or two month nucleation period was needed before whiskers developed. They reached a maximum length of about $1.5 \mathrm{~mm}$ after 6 months and little or no further growth occurred during the subsequent 32 years. Very few whiskers grew on the tin-plated steel samples and no intermetallic formation was observed. None of the fused tin-platings nucleated whiskers during the 32 year period.

Practical implications: Knowledge about vintage whiskers is important in order that we can take steps to increase the resiliency of our space missions. Similarly, such knowledge is important to engineers engaged on products reaching their nominal end-of-life, but where for reasons of economy, these products cannot be replaced

Originality/value: This study represents a unique insight into whisker growth and intermetallic formation over an extremely long time period.

Keywords: Tin; Whisker growth; Electrodeposition; Intermetallic formation;

Characterisation 


\section{Introduction}

Work concerning the characterisation of tin whiskers was initiated at the European Space Agency (ESA) in the mid-1970's (Dunn 1976) but it was not until 1982 that a more rigorous study of whiskers was undertaken as, in this period, a spacecraft electronic circuit was seen to malfunction and tin whiskers were considered to have been a potential cause of short circuiting. The relationship between tin whisker diameter and the applied current needed to cause whisker burn-out was calculated from actual measurements in the laboratory - the vexing problem of short circuiting was also identified when currents could flow through whiskers without burn-out, as shown in Figure 1 (Dunn 1988). Unwanted growths of tin whiskers are known to severely jeopardise the reliability of electronic circuits. This is particularly true when the whiskers grow to long lengths in the order of 1 to $2 \mathrm{~mm}$ and produce electrical short circuits in low voltage equipment. Between 1972 and 1985 laboratory findings at ESA revealed several tin whisker issues on space hardware, tin whiskers were growing from: tin-plated terminal pins designed for soldering (Sn on Cu on brass); a tin plated housing; plated through holes on a pure tin finished printed circuit board; tin plated lugs for crimping and soldering; tin-plated steel springs and contact points on electrical switches; and, vacuum deposited tin on the inside of a plastic back-shell connector protector (Dunn 2009). In 1985 pure tin was prohibited by the contractual requirements of the ESA standards covering the selection of materials for space use and the top level electronic component procurement standards. Tin-lead solder alloys and tin-lead solderable finishes were recommended and space-qualified for ESA electronic systems as it was known that the addition of at least $3 \%$ lead to pure tin, was a reliable mitigation against whisker growth (see for instance ECSS-Q-ST-70-08 (ECSS 2009)). From the mid-80's until the mid-10's, with two notable exceptions, no whisker anomalies have been reported on ESA projects.

Sweeping changes to the electronics manufacturing industry were introduced by the European Parliament and Council in 2006 (The European Parliament and The Council of The European Union 2003). The EU directives such as RoHS now specifically forbid the traditional use of lead in the composition of the components, circuit boards and solders used in the 
assembly of electronic circuits. Commercial electronic equipment should now contain no lead. Although the space, aircraft and medical sectors are presently exempt from the leadfree rules, lead-free items (mainly components having pure tin plated terminations) destined for the vast commercial markets, have also infiltrated the "exempt" high reliability industries. Tin whiskers and the problems they cause have now returned to the stage and hence there is again a need to understand how they grow, how they can create electrical and mechanical failures and particularly, what means can be used to mitigate against their growth.

Financial constraints now necessitate that both professional and commercial electronic systems such as motor vehicles, televisions, computer hardware and the like, incorporate the philosophy of redundant circuits and throw-away modules. This means it is unlikely that any failure analysis will be performed on defective hardware and it appears likely that rejected modules will support ubiquitous colonies of microscopic whiskers that will never be detected during any post-mortem by the 'forensic scientist'.

The laboratory study of tin whisker growth (Dunn 1987) using so-called 'C-ring samples' has been on-going since the samples were manufactured in 1982. This is probably one of the longest whisker study to have been undertaken under strict conditions of isothermal ageing in a non-corrosive environment. An updated analysis of whisker growth was subsequently reported in March 2006 (Dunn 2006). In this present paper we have re-examined the length of whiskers present on the C-rings after 32 years storage. Metallographic work has now been performed to reveal the microstructure and the growth of intermetallic compounds (IMC) at the various plating-to substrate interfaces.

\section{Experimental procedures}

2.1 The Test Specimens, their plated layers and method of stressing

The original report (Dunn 1987) can be consulted for a detailed description of the test specimen. The samples consisted essentially of machined C-rings having the dimensions 
shown in Figure 2. Stress can be applied to these rings by tightening the nuts on the bolt; this is rather similar to C-rings designed for stress corrosion testing (ASTM 2013). The rings were manufactured to represent certain spacecraft electronic systems utilised in the 1970's, but which may also represent unapproved or counterfeit components assembled into today's electronic circuits. The base metals were steel and brass, with and without a nominally $3 \mu \mathrm{m}$ copper barrier layer (occasionally seen to be actually 1.5 or $2 \mu \mathrm{m}$ ).

The final finish was pure, electroplated "normal" tin as used commercially. For some samples the normal tin was fused in a controlled, non-oxidising atmosphere. Two additional variants for the tin plating were designed into the study:

\begin{abstract}
"Abnormal" tin to represent a plating bath depleted in tin and operated at a high current density to provide a deposit with compressive stress, and "Contaminated" bath to represent an electrolyte containing organic contamination (flour dust was used to plate-in occlusions and filtration was not applied to this bath). The plating bath conditions are recorded in Table 1. Three samples of every test variant were produced.
\end{abstract}

Tin whisker growths were thought to result from the application of compressive stress to the plated finish. The C-rings were loaded and this caused them to deflect - the compressive test stresses applied to the various tin platings were:

None, 'slight' (50 MPa) and 'high' (400 MPa).

It will be noted from Figure 2 that these maximum test stresses are applied at $90^{\circ}$ to the Cring axis, so that $\sin \alpha=1$. There will be a progressive reduction in resultant stress along each quadrant as the factor of $\sin \alpha$ tends to zero. Conversely, as the C-rings are loaded their outer surface will be subjected to a range of tensile stresses.

\title{
2.2 Storage Conditions
}

The specimens ( 40 in total) were stored under "isothermal" conditions in a desiccator at 18 $-22{ }^{\circ} \mathrm{C}$. Unlike other tin whisker studies, they were not exposed to thermal cycling or a 
corrosive (from solder flux) environment. The inspection stages were mainly limited to an examination of the compressive inside surfaces of the C-rings. Some observations were recorded relating to the outer tensile loaded surfaces and to the small, high-stress locations where the bolt/washer contacted the outer plated layer.

\subsection{Examination of Whisker Growths}

The C-ring surfaces were examined by visual means using a stereo-zoom binocular microscope and by scanning electron microscopy. Nine inspections stages have been performed since the specimen were plated, commencing at day 3 and finally at day 11,102. A total of 2160 data points have been tabulated. An evaluation of the structure and growth directions have been made using X-ray diffraction and transmission electron microscopy. Those findings and the results of an attempt to produce allotropic transformations in tin whiskers can be seen in the original 1987 report (Dunn 1987).

\subsection{Microstructural Characterisation}

Metallography was also conducted on one sample, covering each specimen variant. The sample was carefully cut from the C-ring with a jeweller's saw. These pieces were mounted in a low exothermic resin and transversely sectioned to reveal the true plating thickness. The microsections were polished and examined by optical and electron microscopy. Scanning electron microscopy (SEM) was carried out using either a Carl Zeiss Leo 1530 VP FEG SEM equipped with an Oxford Instruments X-Max $80 \mathrm{~mm}^{2}$ detector for energy dispersive X-ray spectroscopy (EDS) or a Hitachi TM3030 benchtop scanning electron microscope.

\section{Results}

\subsection{Characterisation of microsectioned 32 year old specimens}

Detailed electron microscopy and elemental analysis has been undertaken to investigate the intermetallic growth present at the interface between the Sn coating and the brass and steel substrates, both with and without a copper barrier layer. These analyses have primarily 
focussed on the 'normal' tin deposits, including those fused after Sn deposition. The results of these analyses are presented in the following sections.

\subsubsection{Sn deposits on brass with and without Cu barrier layers}

The backscattered electron images in Figure 4 show the morphology and thickness of the intermetallic layer formed between 'normal' electroplated Sn coatings and brass substrates with and without $\mathrm{Cu}$ barrier layers. For tin deposited directly onto brass (Figure 4a), the Sn$\mathrm{Cu}$ intermetallic layer is much less uniform than that formed with a copper barrier layer present (Figure 4b); this suggests that $\mathrm{Cu}$ diffusion is enhanced along the tin grain boundaries, which are also more readily identified for the sample deposited without the $\mathrm{Cu}$ barrier layer. It is also evident that the interface between the intermetallic layer and the brass substrate it less planar and also less distinct than that between the intermetallic and the $\mathrm{Cu}$ barrier layer. The different microstructures observed for the Sn coatings result from the diffusion of zinc atoms, originating from the brass C-ring, into the electroplated Sn when there is no Cu barrier layer present. Ashworth et al. (2014) demonstrated that zinc is present on the external surface of a $2 \mu \mathrm{m}$ thick electroplated tin deposit within 24 hours of electroplating, where it subsequently forms a tenacious zinc oxide.

The $\mathrm{x}$-ray maps shown in Figure 5 underline the irregular shape of the Cu-Sn intermetallic and confirm the presence of $\mathrm{Zn}$ along the $\mathrm{Sn}$ grain boundaries and, in particular, at the surface of the $\mathrm{Sn}$ deposit where it is present as $\mathrm{Zn}$ oxide. For the sample with the $3 \mu \mathrm{m} \mathrm{Cu}$ barrier layer the thickness of the intermetallic layer is more uniform with an average thickness of $\sim 2.5 \mu \mathrm{m}$ whilst the thickness of the remaining unreacted Cu layer is $\sim 2.5 \mu \mathrm{m}$. In the presence of the Cu barrier layer, no measureable $\mathrm{Zn}$ diffusion into the $\mathrm{Sn}$ coating is evident; this is supported by SEM/EDX line scan analyses (Figure 6), which show that the extent of $\mathrm{Zn}$ diffusion into the $\mathrm{Cu}$ is limited and that little or no $\mathrm{Zn}$ is present beyond $1 \mu \mathrm{m}$ into the $\mathrm{Cu}$ barrier layer. Copper has a relatively low diffusion rate though tin plating and 'barrier layers' of copper are effective in the prevention of zinc reaching the solderable surfaces of electronic parts. 
Only a single type of intermetallic phase is observed for both Sn deposits on brass and Sn deposits on brass with the Cu barrier layer. For Sn deposits on brass, the average composition of the intermetallic phase is $49.9 \pm 1.5 \mathrm{Cu}, 46.2 \pm 3.5 \mathrm{Sn}$ and $3.9 \pm 2.9 \mathrm{Zn}$ (at \%) whilst for Sn deposits on brass with the Cu barrier layer its average composition is $51.7 \pm 1.4$ $\mathrm{Cu}, 47.5 \pm 1.4 \mathrm{Sn}$ and $0.8 \pm 0.2 \mathrm{Zn}$ (at \%). In both cases, the analysed composition of the intermetallic phase is consistent with it being $\mathrm{Cu}_{6} \mathrm{Sn}_{5}$.

For samples fused after Sn deposition (Figure 7), a distinct difference in intermetallic formation is observed for samples with and without the $\mathrm{Cu}$ barrier layer present. For the fused tin samples deposited directly onto brass two distinct layers are observed (Figure 7a). The first layer (Layer 1 in Figure 7a), adjacent to the brass substrate, has a uniform thickness of $\sim 1.5 \mu \mathrm{m}$ and is shown by EDX mapping (Figure 8 ) to contain $\mathrm{Zn}$ in addition to $\mathrm{Cu}$ and $\mathrm{Sn}$. The approximate composition of this layer is $43 \% \mathrm{Cu}, 21 \% \mathrm{Sn}$ and $36 \% \mathrm{Zn}$ (all at\%). Beneath this layer, a region slightly enriched in $\mathrm{Cu}$ and depleted in $\mathrm{Zn}$ is present within the brass. The intermetallic layer adjacent to the Sn coating (Layer 2 in Figure 7a) is thinner and generally less uniform with globular islands extending into the Sn deposit. EDX mapping (Figure 8) indicates that this layer is comprised predominantly of $\mathrm{Cu}$ and $\mathrm{Sn}$ with the $\mathrm{Zn}$ content $(<10$ at\%) greatly reduced compared with layer 1 . Evidence of zinc oxide formation, similar in morphology to that shown in Figure 5, has also been observed at the surface of fused tin deposits on brass.

For the fused Sn deposit with the Cu barrier layer islands of globular intermetallic are present dispersed throughout the entire thickness of the Sn coating, as shown in Figure 9. In addition, an approximately uniform layer of intermetallic is present at the interface, which is comparable in thickness to that formed on the unfused sample (Figure 4b). EDX analysis shows that the composition of the intermetallic phase at the interface between the fused $\mathrm{Sn}$ and the Cu barrier layer is approximately $43 \% \mathrm{Cu}$ and $57 \% \mathrm{Sn}$ (at\%). In comparison, the intermetallic phase present within the fused tin coating has a tin content that is 10 at $\%$ higher than that of the interfacial intermetallic, i.e. 33\% Cu and 67\% Sn (at\%). SEM/EDX mapping (Figure 9) shows that with the $\mathrm{Cu}$ barrier layer present no measurable Zn diffusion 
into the fused Sn deposit occurs and consequently no zinc oxide is observed at the deposit surface.

\subsubsection{Sn deposits on steel with and without Cu barrier layers}

Backscattered electron images showing the interface microstructure of 'normal' Sn deposits on steel, with and without Cu barrier layers, are shown in Figure 10. Higher resolution secondary electron images of the interface microstructure are shown in Figure 11. For Sn deposited directly onto the steel substrate (Figures 10a and 11a) there is no clear evidence of intermetallic formation after 32 years storage at room temperature. For the sample with the Cu barrier layer (Figures $10 \mathrm{~b}$ and $11 \mathrm{~b}$ ), the Sn-Cu intermetallic, shown by EDX analysis to be $\mathrm{Cu}_{6} \mathrm{Sn}_{5}$ with an average composition of $53.4 \pm 1.3$ at\% $\mathrm{Cu}$ and $46.6 \pm 1.3$ at\% $\mathrm{Sn}$, is relatively planer and similar in both thickness and morphology to that formed for the $\mathrm{Sn}$ deposits on brass with the Cu barrier layer. The average thickness of the intermetallic layer is $\sim 2.2 \pm 0.5 \mu \mathrm{m}$ whilst the thickness of the unconsumed Cu barrier layer is $\sim 2.5 \mu \mathrm{m}$, i.e. comparable to that observed for the Sn deposits on brass with the Cu barrier layer. The EDX maps shown in Figure 12 indicate that little, if any, interdiffusion has occurred between the Cu barrier layer and the steel substrate. In the case of the fused Sn deposit on steel, fine FeSn intermetallic particles are present at the interface (Figure 11c). The precise composition of these features is not known since their fine scale precludes accurate compositional analysis by SEM+EDX techniques. For the fused Sn deposit on steel with the Cu barrier layer present (Figure 10d), intermetallic formation is similar to that observed for the Sn deposit on brass with the Cu barrier layer, i.e. large discrete globular intermetallic particles are present within the Sn coating in addition to the relatively planer layer of intermetallic at the interface. Typically, the intermetallic present within the Sn coating has a slightly higher Sn content than the intermetallic present at the interface ( 51 at\% Sn compared with $\sim 47$ at\% Sn). It is interesting to note that the potential for continued whisker growth remains even after 32 years storage. This is demonstrated by the growth of new whiskers on freshly prepared cross sections, an example of which is shown in Figure 13 for a Sn deposit on steel with a Cu barrier layer. 


\subsection{Evaluation of whisker growth}

Tin whiskers have been seen to nucleate and grow from all of the as-plated C-ring surfaces. The nucleation period prior to growth was short for those tin platings that had been applied either directly onto a brass substrate or to a copper intermediate layer. The "normal" commercial tin plating was observed to support the largest initial rates of growth, followed by the "abnormal" high current density tin-plating. The lengths of these whiskers were in excess of $0.5 \mathrm{~mm}$ after a shelf life of only 2 months. The tin-plated steel with a copper barrier, like those of brass with a copper barrier, grew to lengths in the order of $4.5 \mathrm{~mm}$ when examined at the 32-year inspection. Whiskers grown on both tin plated brass and tin plated steel with a Cu barrier layer possessed a wide range of growth morphologies including straight filaments, kinked filaments, multidirectional whiskers and odd shaped eruptions. Examples of the various growth morphologies, observed during the last inspection, are shown in Figures 14 and 15 for tin plated steel with a copper barrier layer and tin plated brass, respectively. The organically contaminated platings were slow to nucleate whiskers and needed between 6 months and 3 years before any whiskers nucleated, they then grew during the next 12 years to lengths of between 1 and $2.2 \mathrm{~mm}$. The "normal" tin plating made directly to the mild steel substrates incurred extremely long nucleation periods of approximately 6 months. No whiskers were seen to nucleate on any of the fused tin-plated layers.

An attempt was made to calculate the whisker density on the samples, but this was abandoned because of the random nature of growths and the fact that this task would be exceedingly time-consuming. Several estimates were made, they ranged from 0.1 to $200 / \mathrm{mm}^{2}$. For completeness, all of the inspection results have been compiled into Tables 2 6 ; in the tables (V) refers to visual inspection at 80x magnification whilst (S) refers to SEM inspection.

\section{Discussion}


The measured length of the longest whisker as a function of storage time is plotted in Figure 16 for the "normal" tin deposits on brass and steel with and without a copper barrier layer present. Results show that with a barrier layer present, whisker growth for tin deposits on brass and steel was comparable, i.e. the rate and extent of whisker growth was independent of the substrate material and solely determined by the growth of the $\mathrm{Cu}_{6} \mathrm{Sn}_{5}$ intermetallic at the Cu-Sn interface due to the limited diffusion of both $\mathrm{Zn}$ and Fe into the Cu barrier layer and their absence within the tin coating. Figure 16 also shows that the onset of whisker growth occurred more quickly, and the maximum whisker length was greater, for tin deposits on brass compared with the other samples. This observation is consistent with other studies that have demonstrated increased whisker growth for tin deposits on brass compared with tin deposits on copper (Britton \& Clarke 1964; Ashworth et al. 2014; Ashworth et al. 2015). Increased whisker growth for tin deposits on brass can be attributed to $\mathrm{Zn}$ diffusion into the tin from the underlying substrate with the subsequent formation of zinc oxide at the deposit surface (Ashworth et al. 2014). Although it is generally accepted that $\mathrm{Sn}$ deposits on brass are more susceptible to whisker growth than those on $\mathrm{Cu}$, there have been reports of reduced whisker growth for tin deposits on brass compared with $\mathrm{Cu}$ (Miller et al. 2010, Stein et al. 2014). In each of these papers the authors attributed a decrease in whisker growth to a reduction in the rate at which the $\mathrm{Cu}_{6} \mathrm{Sn}_{5}$ intermetallic was formed, i.e. the presence of $\mathrm{Zn}$ suppressed the growth of the $\mathrm{Cu}_{6} \mathrm{Sn}_{5}$, thereby reducing the levels of compressive stress developed within the deposit. In the present study, although there is a clear difference in the morphology of the intermetallic formed between tin deposits on brass and those on $\mathrm{Cu}$ (Figure 4) the amount of intermetallic formed is comparable. It should be noted that neither of the aforementioned papers considered the impact of Zn diffusion into the tin deposit on whisker growth. With the $3 \mu \mathrm{m} C u$ barrier layer present, Zn diffusion into the Sn deposit is limited, even over a 32 year timescale (Figure 6), and the additional driving force for whisker growth is removed. For tin deposits on steel without a barrier layer no intermetallic formation is observed, even after 32 years ambient storage, and only very limited whisker growth is observed $(\sim 20 \mu \mathrm{m})$. For fused tin deposits on steel, although fine $(<1 \mu \mathrm{m})$, discrete intermetallic particles are present at the interface, 
no whisker growth is observed. In the case of fused tin deposits on brass, no whisker growth was observed, irrespective of whether a copper barrier layer was present or not.

For tin deposits onto brass and steel with the Cu barrier layer present the thickness of the intermetallic layer after 32 years storage was $\sim 2.5 \mu \mathrm{m}$ in both cases. This suggests that the $\mathrm{Cu}_{6} \mathrm{Sn}_{5}$ functions as an effective diffusion barrier to the continued formation of intermetallic compound such that a significant proportion of the $\mathrm{Cu}$ barrier layer remains unreacted even after 32 years storage at room temperature. It is also interesting to note that the intermetallic layer is relatively planar and does not possess an overtly pronounced 'wedgeshaped' morphology that is often associated with an increased propensity for whisker growth (Baated et al. 2011; Kim et al. 2008).

The risks associated with tin plated finishes are well documented and growths continue to be observed despite the fact that electroplating bath chemistries have been modified and marketed as producing whisker-free deposits. It is essential that steps are taken, as proposed by ESA (Dunn 2012), to effectively mitigate against whisker growths should tin plating continue to be selected as a finish applied to electronic products destined for high reliability applications. It is unlikely that short-term observations or accelerated test methods can determine whether samples with tin plated finishes will be susceptible to whisker growths because they are unable to truly replicate the metallurgical conditions associated with ageing or the associated time-dependant microstructural changes that during service life. These changes have been observed and recorded during the 32-years of the present study. Nucleation periods were often recorded to be in the order of six months, and one unusual sample within the study required 12 years before the commencement of profuse whiskering (with growths of up to $1.8 \mathrm{~mm}$ in length). Certainly, as the gaps between fine pitch leads or the tracks on printed circuit boards become smaller, there will be a greater chance that tin whiskers either bridge these electrical conductors or make whiskerto-whisker contact and electrical short circuits. The most vexing shorts will be those with intermittent properties without whisker burn-out, as depicted in Figure 1. The ability of whiskers to make contact and then conduct an electrical current was the focus of a study by 
Han et al ( 2010 ) using gold- and tin-plated tungsten probes applied to the surfaces of various tin whisker samples. Accurate breakdown voltages were measured against probe pressure. It was found that different contact forces produced a variety of current - voltage transitions together with different breakdown voltages. The variability of results was attributed to the presence of naturally occurring growths of non-conducting tin oxide on individual whiskers. The presence and thickness of oxide formation is known to increase with storage time. Whiskers grown within two weeks have been found to support a dual oxide film of stannous and stannic oxides with a total thickness of $2 \mathrm{~nm}$, whereas the old whiskers described in this present work, have a dual oxide film of 20-30 nm (Dunn and Mozdzen 2014). Whiskers and their oxide films were also studied by Courey, et al (2008) using SEM and focused ion beam milling and they developed an empirical model quantifying the probability of electrical shorting as a function of voltage.

The throw-away philosophy adopted by most commercial industries means that electronic circuits which fail due to whisker growths are not as-such identified; consequently, the reason why any failure happens is not recorded for statistical purposes. It is only when financial resources are available, such as those within the budgets of space-related industries, that attempts can be made to establish the actual failure mode of a given electronic circuit. At least four multi-million dollar communications satellites have failed due to tin whisker-induced short circuits and tin-plasma arcing under the vacuum environment of space. Laboratory activities are essential as the findings from failure mode analyses may avert the loss of future spacecraft. Space hardware is now designed to incorporate miniaturised electronic circuits with PCBs populated with components that have increasingly finer pitched leads. Such systems are often designed for at least 15 year-lives and probes intended to reach the outer boundaries of our Solar System do operate for more than 40 years. The same life-spans are covered by our on-ground activities into the tin whisker growth phenomenon.

\section{Conclusions}


1. For normal tin electroplated onto brass, a one or two month nucleation period was needed before whiskers were seen to develop. They reached a maximum length of about $1.5 \mathrm{~mm}$ after 6 months. Little or no growth occurred during the intervening 30 years. However, deposits from contaminated tin baths needed up to 3 years before nucleation, and these whiskers subsequently grew to lengths of up to $2.2 \mathrm{~mm}$.

2. Extensive zinc oxide formation was observed at the surface of normal tin deposits after storage for 32 years. The introduction of a $\mathrm{Cu}$ barrier layer to brass substrates reduced the rate of whisker growth by inhibiting zinc diffusion into the Sn deposit and thereby preventing the formation of zinc oxide on the surface of the deposit.

3. Normal tin plated samples with a copper barrier layer nucleated whiskers within 5 months and these grew to lengths between 1 and $4.5 \mathrm{~mm}$. For tin deposits on brass and steel with a copper barrier layer whisker growth was comparable; due to the fact that comparable intermetallic compound formation occurred in both cases and elemental diffusion from the substrate into the Sn deposit was supressed.

4. Contaminated tin on copper gave an unexpected result: one sample only nucleated whiskers during the final 12 years storage and they grew to $1.8 \mathrm{~mm}$.

5. After 32 years storage, the $\mathrm{Cu}_{6} \mathrm{Sn}_{5}$ intermetallic layer was $\sim 2.5 \mu \mathrm{m}$ thick for both $\mathrm{Sn}$ deposits on brass and Sn deposits on steel with a copper barrier layer. In both cases a significant fraction of the original Cu plating remained unreacted.

6. None of the fused tin-platings nucleated or grew whiskers during the 32 years storage period (i.e. fused tin on brass, copper-plated brass and steel). The absence of whisker growth for these samples results from the formation of a more uniform intermetallic compound at the interface and the removal of the as-deposited tin microstructure. For the fused tin deposits on brass the formation of the intermetallic layer during the fusing process most likely serves to inhibit subsequent $\mathrm{Zn}$ diffusion through the Sn deposit, thereby mitigating whisker growth. In the case of fused tin deposits on steel only fine scale $(\sim 1 \mu \mathrm{m})$ discrete intermetallic growth is observed.

7. Only very limited ( $20 \mu \mathrm{m})$ whisker growth was observed for tin deposits on steel and after 32 years no intermetallic formation was observed. 
8. Whiskers are seen to possess numerous morphologies, including straight and multidirectional filaments, and typically have diameters ranging from 1 to $20 \mu \mathrm{m}$. Their density appears to vary from about 0.1 to $200 / \mathrm{mm}^{2}$.

9. If tin plating continues to be selected as a finish for high reliability electronic products it seems essential that methods for mitigating against whisker growth are developed and applied in order to minimise the occurrence this mode of failure. 


\section{References}

Ashworth, M.A. et al.,(2014), "An investigation into zinc diffusion and tin whisker growth for electroplated tin deposits on brass", Journal of Electronic Materials, 43(4), pp.1005-1016.

Ashworth, M.A. et al., (2015), "The effect of electroplating parameters and substrate material on tin whisker formation", Microelectronics Reliability, 55(1), pp.180-191

ASTM, (2013), Standard practice for making and using C-ring stress-corrosion test specimens, ASTM G38-01

Baated, A., Kim, K.-S. \& Suganuma, K., (2011), "Effect of intermetallic growth rate on spontaneous whisker growth from a tin coating on copper", Journal of Materials Science: Materials in Electronics, 22(11), pp.1685-1693

Britton, S.C. \& Clarke, M., (1964), "Effects of Diffusion from Brass Substrates Into Electrodeposited Tin Coating on Corrosion Resistance and Whisker Growth", Transactions of the Institute of Metal Finishing, 40, pp.205-211

K.J. Courey et al., (2008) "Tin Whisker Electrical Short Circuit Characteristics- Part 1", IEEE Trans. Electron. Packag. Manuf. , vol. 31, Jan, pp. 32-40

Dunn, B.D., (1976), Whisker formation on electronic materials. Circuit World, 2(4), pp.32-40

Dunn, B.D., (1987), "A laboratory study of tin whisker growth". European Space Agency Report STR-223, European Space Agency, Paris, France

Dunn, B.D., (1988), "Mechanical and electrical characteristics of tin whiskers with special reference to spacecraft systems" ESA Journal, 12, pp.1-17

Dunn, B.D., (2006) "151/2 years of tin whisker growth", ESTEC Materials Report 4562, Noordwijk, the Netherlands

Dunn, B.D., (2009)," An overview of whisker problems on ESA space hardware", in 3rd International Symposium on Tin Whiskers, Lyngby, Denmark

Dunn, B.D., (2012), “Guidelines for a lead-free control plan”, ESA STM-281. October, available at: http//esamultimedia.esa.int/multimedia/publications/STM-281/

Dunn, B.D. and Mozdzen G., (2014),"Tin oxide coverage on tin whisker surfaces, measurements and implications for electronic circuits", Soldering \& Surface Mount Technology, Vol. 26 Iss 3 pp. 139 - 146

ECSS Secretariat, (2009), ECSS-Q-ST-70-08C (2009) Space Product Assurance: The manual soldering of high-reliability electrical connections, ESA-ESTEC

Han, S., Osterman, M. and Pecht, M.G., (2010), "Electrical Shorting Propensity of Tin Whiskers”, IEEE Trans. Electron. Packag. Manuf. , vol. 33, July, pp. 205-211. 
Kim, K.S. et al., (2008), "Investigation of relation between intermetallic and tin whisker growths under ambient condition", Microelectronics Reliability, 48(1)

Miller, S.M., Sahaym, U. \& Norton, M.G., (2010), "Effect of Substrate Composition on Sn Whisker Growth in Pure Sn Films", Metallurgical and Materials Transactions a-Physical Metallurgy and Materials Science, 41A(13), pp.3386-3395

Stein, J. et al., (2014), "Microstructural Development and Possible Whiskering Behavior of Thin Sn Films Electrodeposited on Cu(Zn) Substrates", Journal of Electronic Materials, 44(3)

The European Parliament and The Council of The European Union, (2003), Directive 2002/95/EC of the European Parliament and the Council of 27 January 2003 on the restriction of the use of certain hazardous substances in electrical and electronic equipment, Official Journal of the European Union, 46(February), p.L37 19-23 


\section{List of Figures}

Fig. $1 \mathrm{Graph}$ to illustrate the effect of whisker diameter on possible short circuiting whisker (from plots of $\mathrm{mA}$ vs $\mathrm{mV}$ for four whiskers, relationship is linear until heating effects cause whisker burn out). These measurements were made on actual whiskers. Whisker currents depicted in 'region C' could account for the intermittent short-circuits encountered on spacecraft equipment.

Figure 2 Overall dimensions for C-ring specimens. $\mathrm{W}=$ width $=25 \mathrm{~mm}, \mathrm{~h}=$ thickness $=2 \mathrm{~mm}$, $\mathrm{a}=$ outside radius $=12.5 \mathrm{~mm}, \mathrm{~b}=$ inside radius $=10.5 \mathrm{~mm}$

Figure 3 Optical photograph of typical C-ring. Some long whisker growths can be discerned on both the inner and outer surfaces.

Figure 4 Backscattered electron images showing the interfacial regions of normal Sn deposits on brass after storage at room temperature for 32 years: (a) $5 \mu \mathrm{m}$ Sn deposit, (b) 5 $\mu \mathrm{m}$ Sn deposit with a $3 \mu \mathrm{m}$ Cu barrier layer

Figure 5 SEM/EDX analysis of a cross-sectioned Sn deposit on brass after storage at room temperature for 32 years: (a) secondary electron image, (b) Sn L $\alpha$ x-ray map, (c) Cu K $\alpha$ xray map, (d) Zn K $\alpha$ x-ray map and (e) Pb M $\alpha$ x-ray map

Figure 6 SEM/EDX line scan showing the elemental distribution across the interfacial regions of a $5 \mu \mathrm{m}$ Sn deposit on brass having a $3 \mu \mathrm{m}$ Cu barrier layer after storage at room temperature for 32 years

Figure 7 Secondary electron images showing the extent of intermetallic formation for fused 'normal' Sn deposits on brass after storage at room temperature for 32 years: (a) $5 \mu \mathrm{m}$ fused Sn deposit and (b) $5 \mu \mathrm{m}$ fused Sn deposit with a $3 \mu \mathrm{m}$ Cu barrier layer.

Figure 8 SEM/EDX analysis of a cross-sectioned fused Sn deposit on brass after storage at room temperature for 32 years: (a) secondary electron image, (b) Sn L $\alpha$ x-ray map, (c) Cu K $\alpha$ x-ray map, (d) Zn K $\alpha$ x-ray map

Figure 9 SEM/EDX analysis of a cross-sectioned fused Sn deposit on brass with a $3 \mu \mathrm{m} \mathrm{Cu}$ barrier layer after storage at room temperature for 32 years: (a) secondary electron image, (b) Sn L $\alpha$ x-ray map, (c) Cu K $\alpha$ x-ray map, (d) Zn K $\alpha$ x-ray map

Figure 10 Back-scattered electron images showing the extent of intermetallic formation for normal Sn deposits on steel after storage at room temperature for 32 years: (a) $5 \mu \mathrm{m} \mathrm{Sn}$ deposit, (b) $5 \mu \mathrm{m}$ Sn deposit with a $3 \mu \mathrm{m}$ Cu barrier layer, (c) a fused $5 \mu \mathrm{m}$ Sn deposit and (d) a fused $5 \mu \mathrm{m}$ Sn deposit with a $3 \mu \mathrm{m}$ Cu barrier layer

Figure 11 High magnification secondary electron images showing the interface regions of normal Sn deposits on steel after storage at room temperature for 32 years: (a) $5 \mu \mathrm{m}$ Sn deposit, (b) $5 \mu \mathrm{m}$ Sn deposit with a $3 \mu \mathrm{m}$ Cu barrier layer and (c) a fused $5 \mu \mathrm{m}$ Sn deposit 
Figure 12 SEM/EDX analysis of a cross-sectioned Sn deposit on steel with a $3 \mu \mathrm{m}$ barrier layer after storage at room temperature for 32 years: (a) secondary electron image, (b) Sn L $\alpha x$ ray map, (c) Cu K $\alpha$ x-ray map, (d) Fe K $\alpha$ x-ray map

Figure 13 Secondary electron image showing whisker growth from the polished surface of a cross-sectioned Sn deposit on steel with a $3 \mu \mathrm{m}$ Cu barrier layer

Figure 14 Scanning electron microscope images from the last inspection of a normal Sn deposit on steel with a $3 \mu \mathrm{m}$ Cu barrier layer (sample 30), showing (a) a typical straight filament whisker having, (b) a kinked portion at its base, (c) an irregular tip and (d) multidirectional growth

Figure 15 Scanning electron microscope images from the last inspection of a Sn deposit on brass (sample 8), showing (a) three whiskers of varying diameters, from $1 \mu \mathrm{m}$ (short length), $2 \mu \mathrm{m}$ long length and $20 \mu \mathrm{m}$ appearing as a stubby eruption and (b) a whisker density of about $90 / \mathrm{mm}^{2}$

Figure 16 Graph comparing the length of the longest whisker as a function of storage time at room temperature for unstressed normal tin deposits on brass and on steel with and without a copper barrier layer present 


\section{List of Tables}

Table 1 Bath conditions for the various platings (Note. All chemical analyses were confirmed by analysis reports from the Oxymetals Benelux Laboratory).

Table 2 Evaluation of whisker growth on tin-plated brass substrate. * longer whiskers were broken and many more nodules were present

Table 3 Evaluation of whisker growth on tin-plated brass with copper barrier. * whisker observed on the outside surface of c-ring

Table 4 Evaluation of whisker growth on tin plated steel substrate.

Table 5 Evaluation of whisker growth on tin plated steel with copper barrier. * whisker observed on the outside surface of c-ring

Table 6 Evaluation of whisker growth on fused tin platings. 


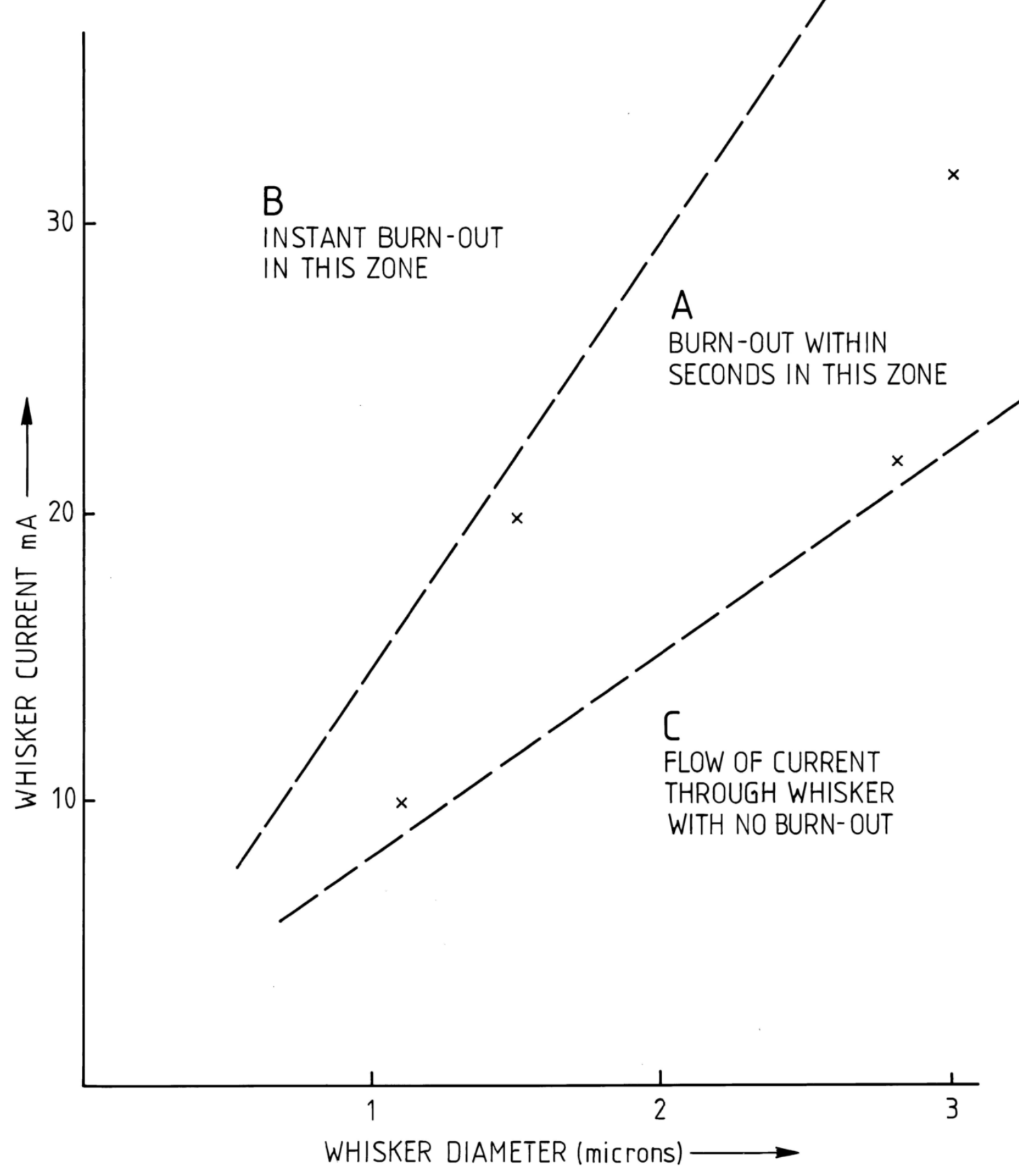

Figure 1 


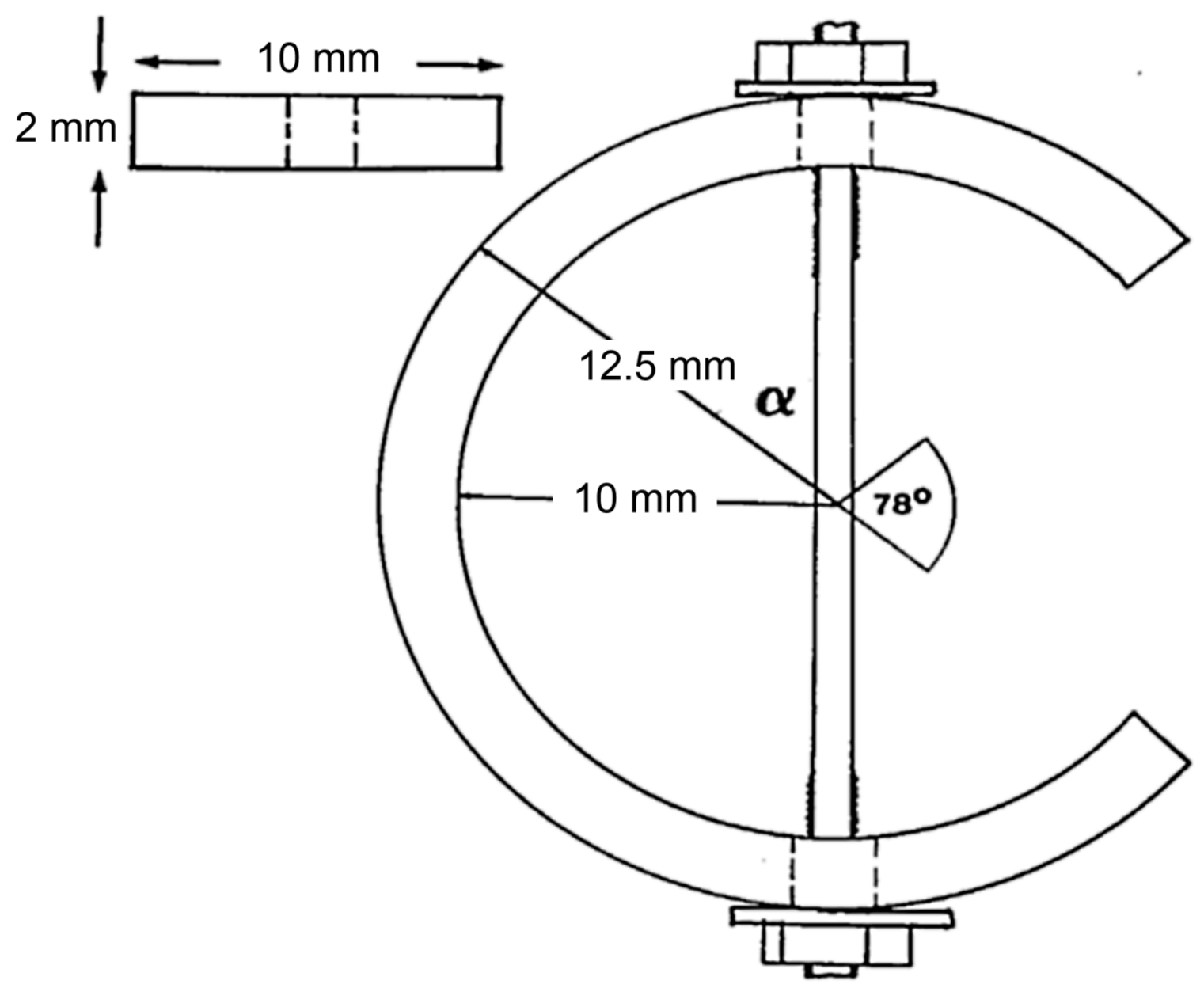

Figure 2 


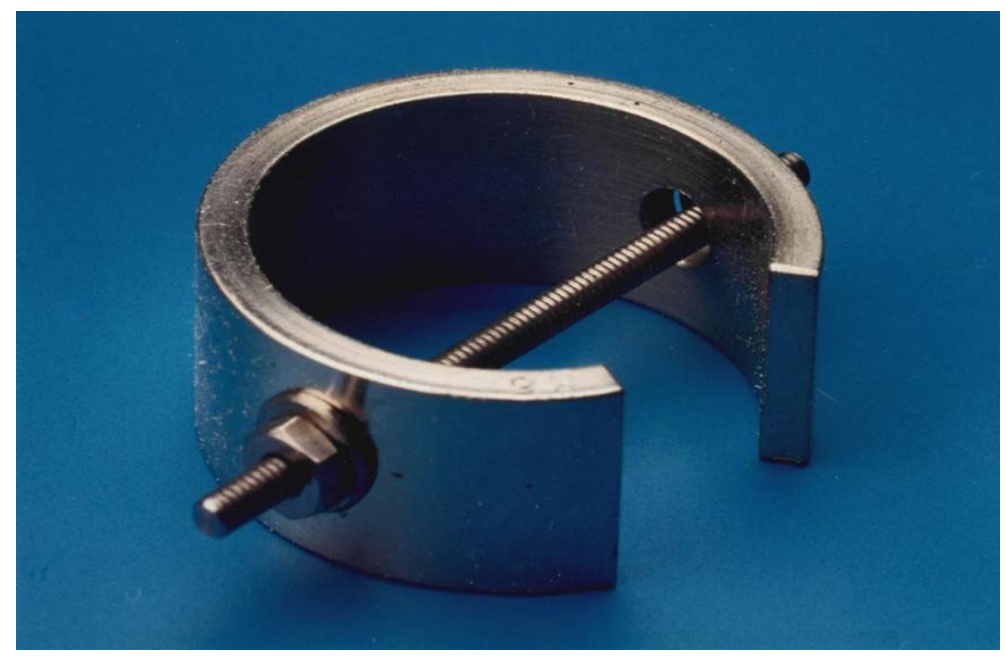

Figure 3 


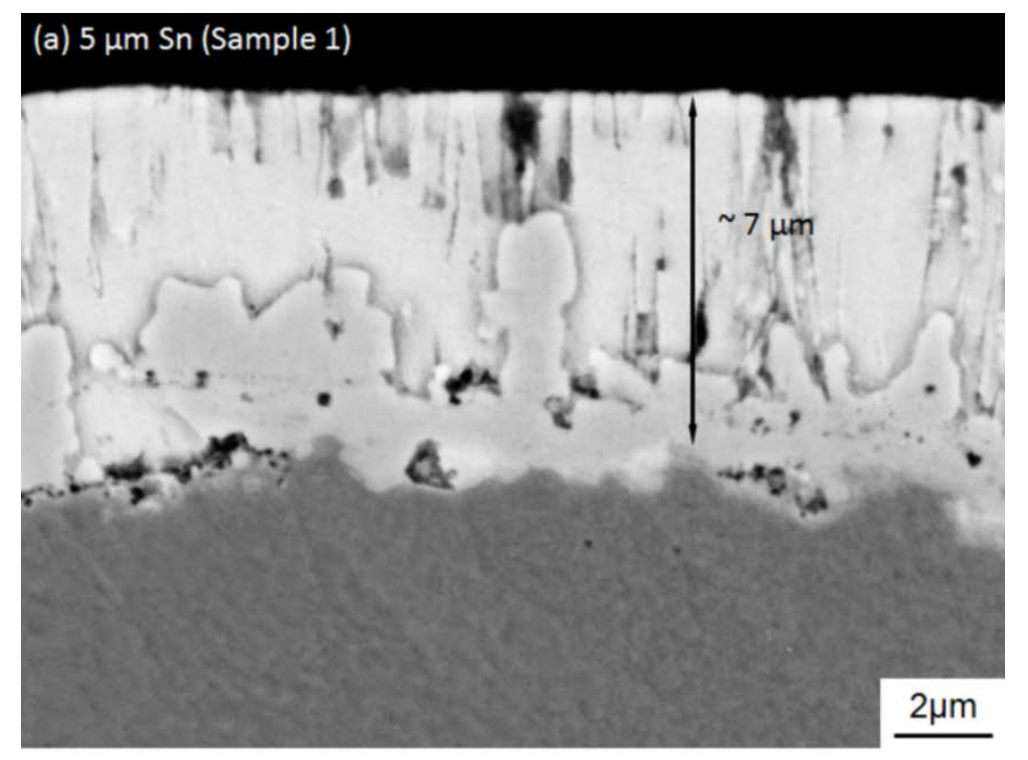

\section{(b) $3 \mu \mathrm{m} \mathrm{Cu+5} \mu \mathrm{m}$ Sn (Sample 10)}

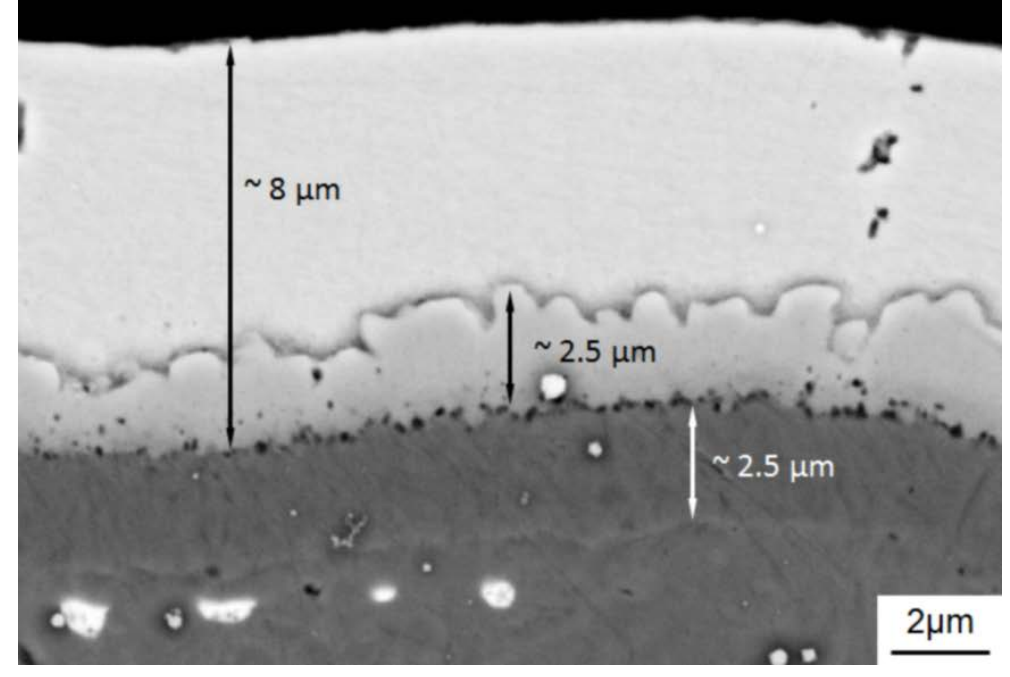

Figure 4 


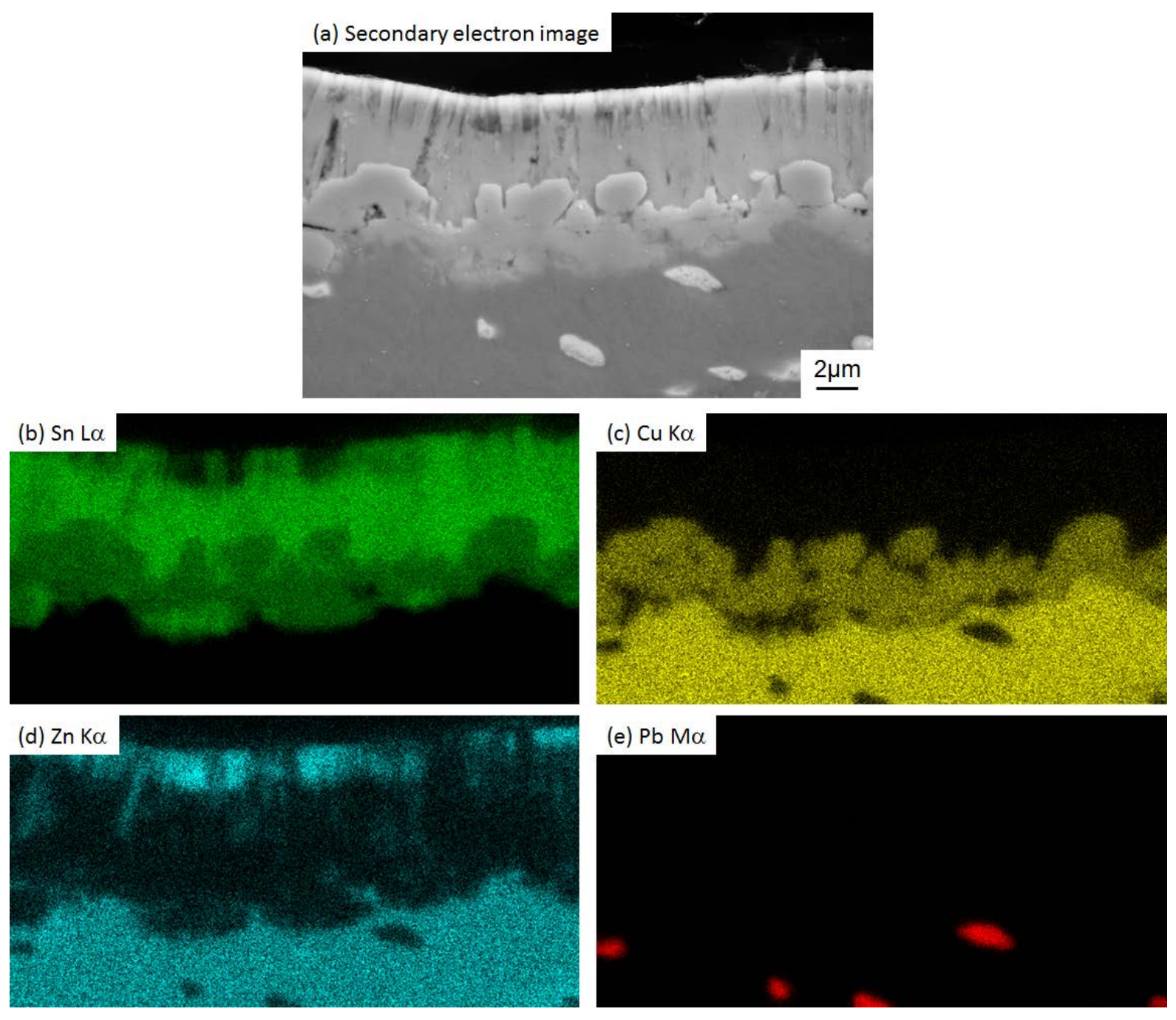

Figure 5 


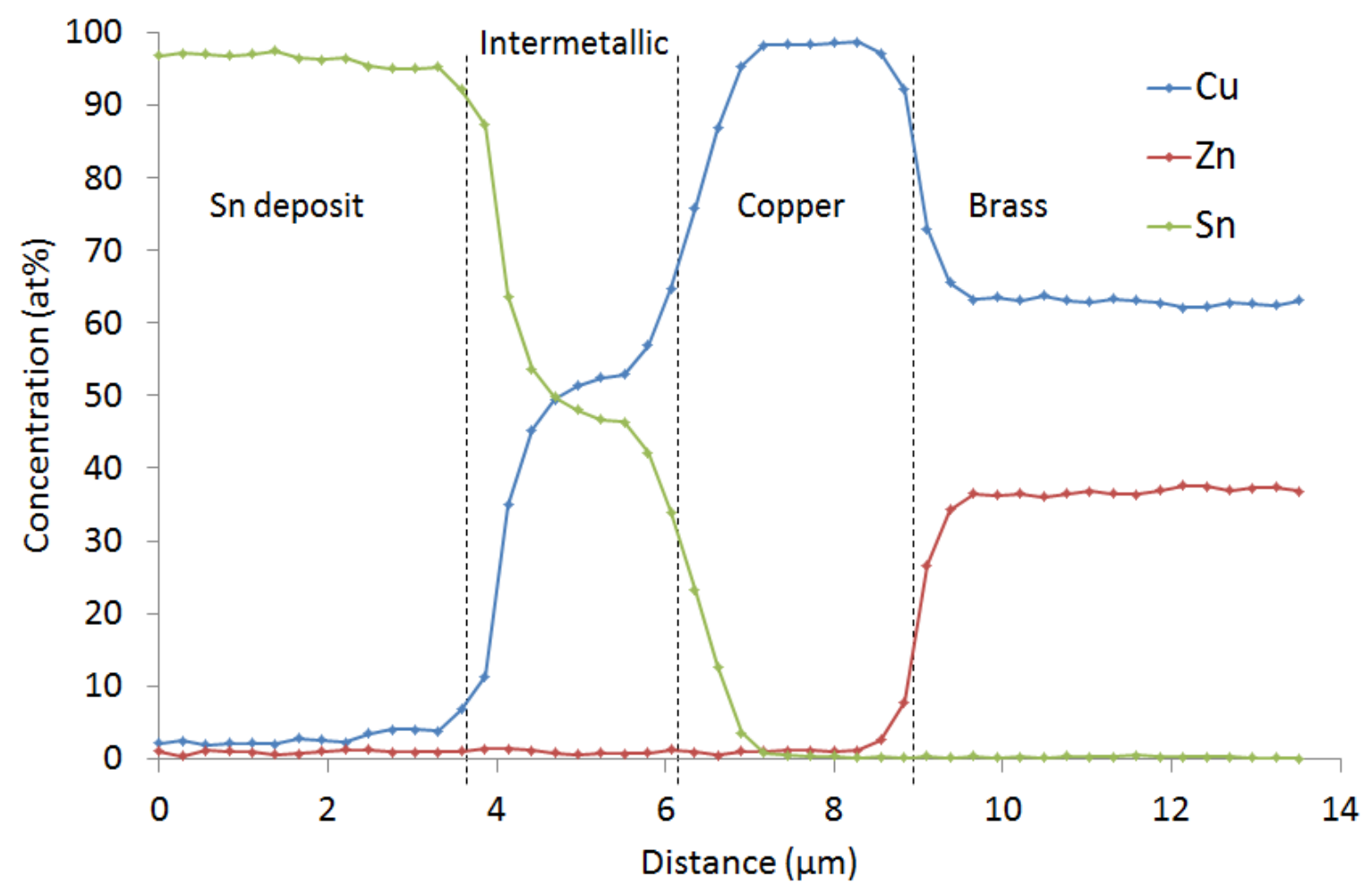

Figure 6 
(a) Fused $5 \mu \mathrm{m}$ normal Sn (Sample 19)

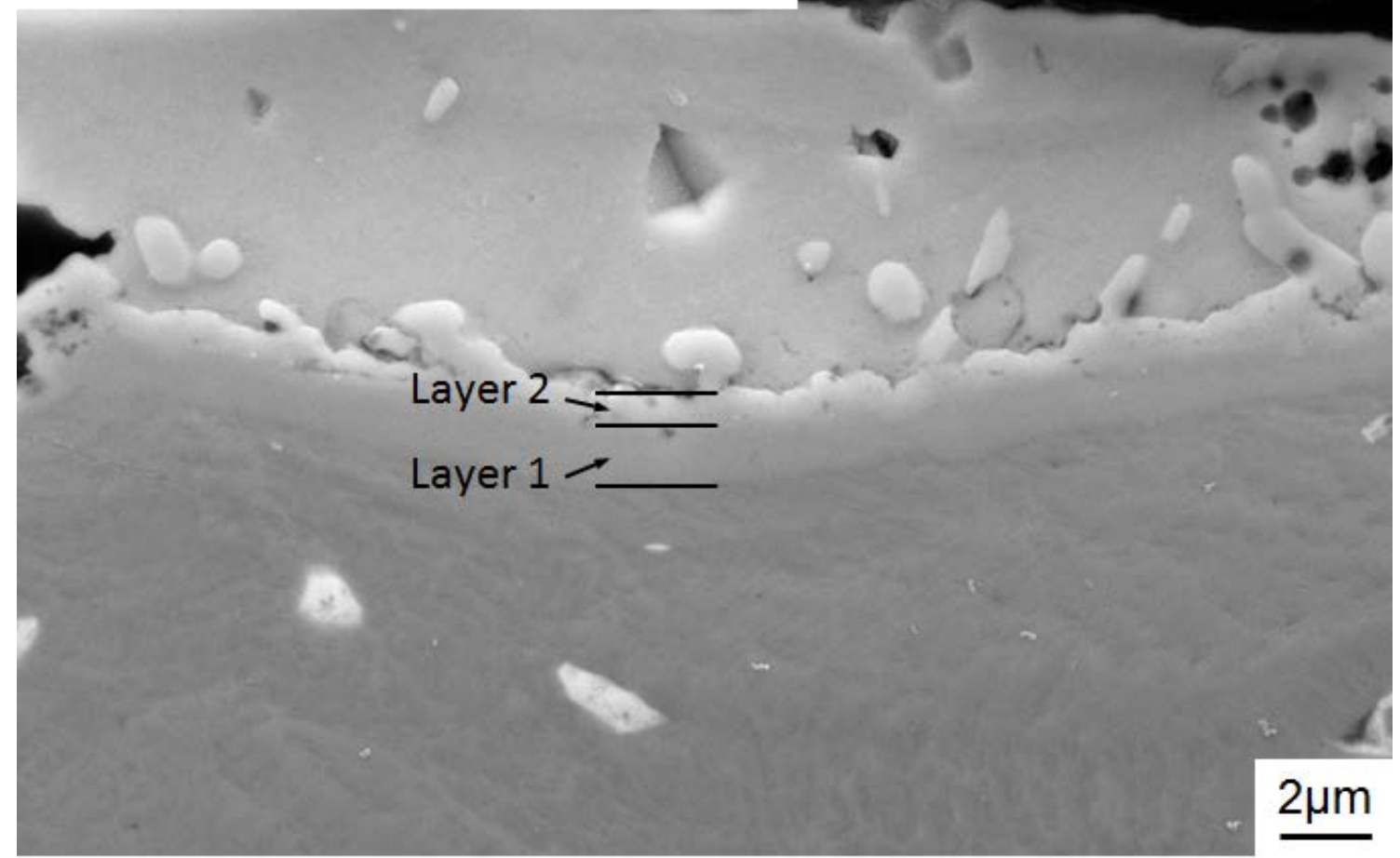

(b) Fused $5 \mu \mathrm{m}$ normal $\mathrm{Sn}+3 \mu \mathrm{m}$ Cu (Sample 20)

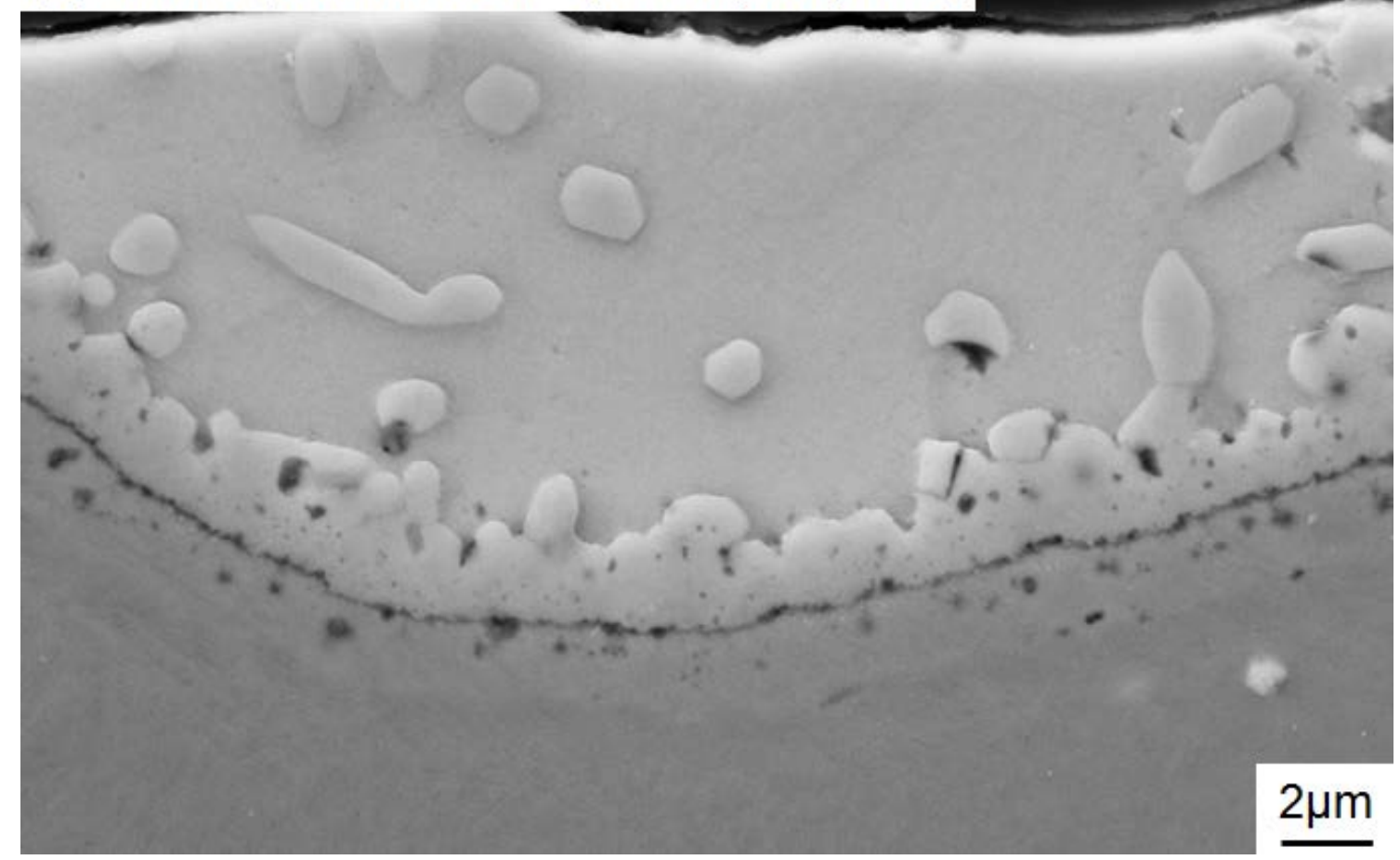

Figure 7 
(a) Secondary electron image
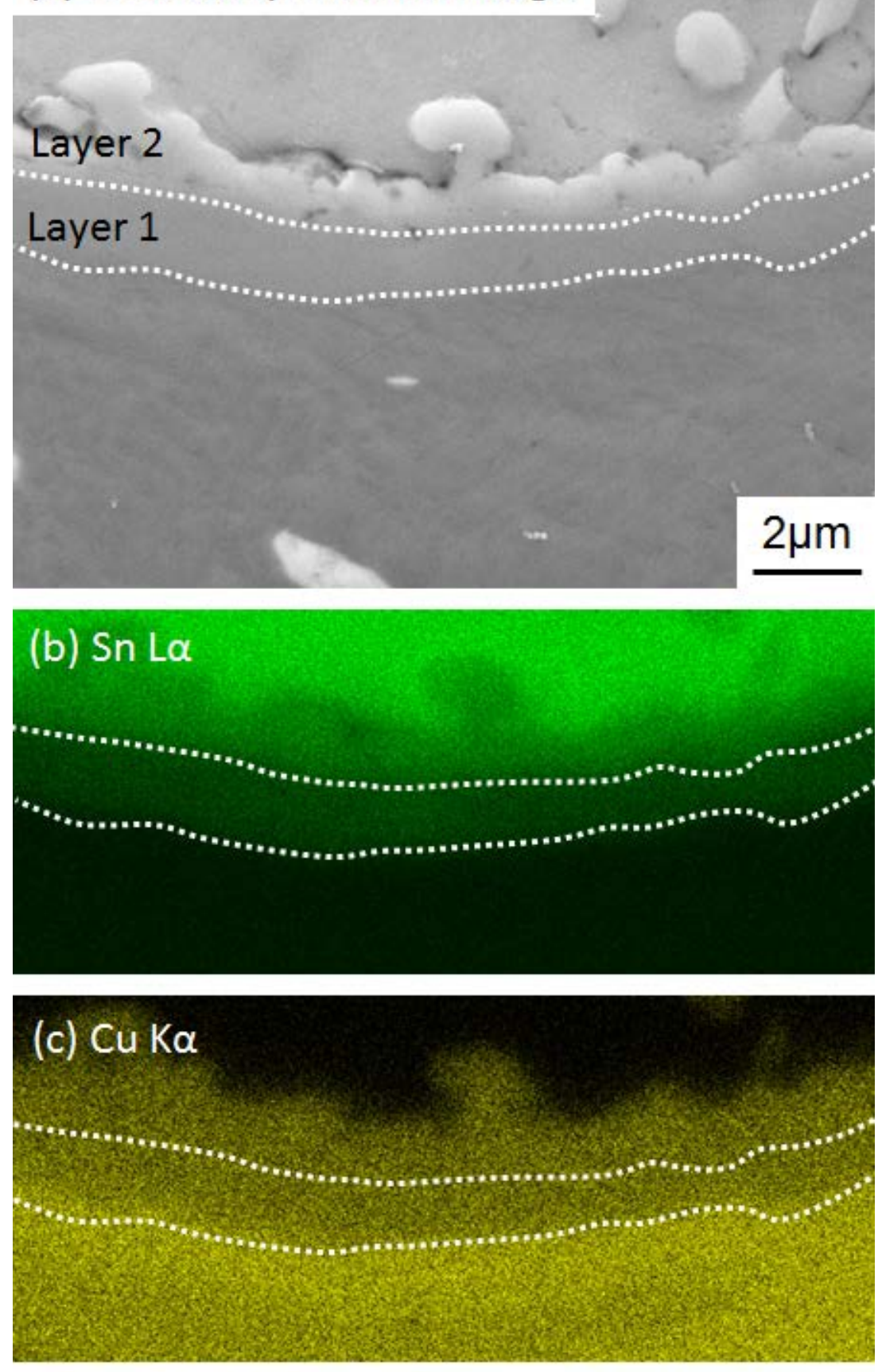

\section{(d) $\mathrm{Zn} \mathrm{K \alpha}$}

Figure 8 


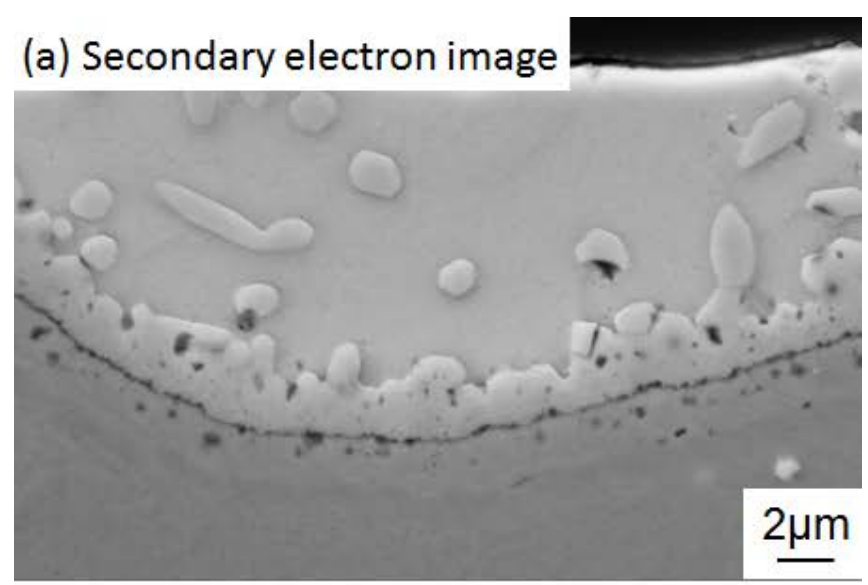

(b) Sn L $\alpha$
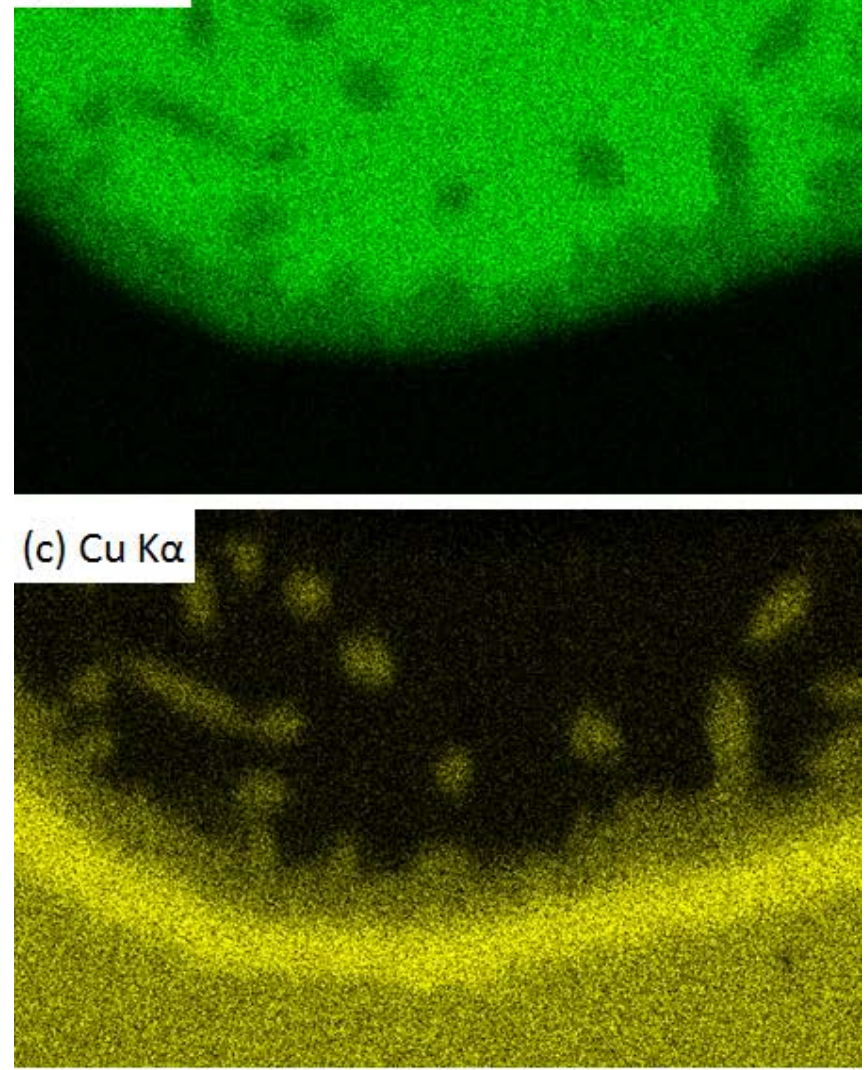

(d) $\mathrm{Zn} \mathrm{K \alpha}$

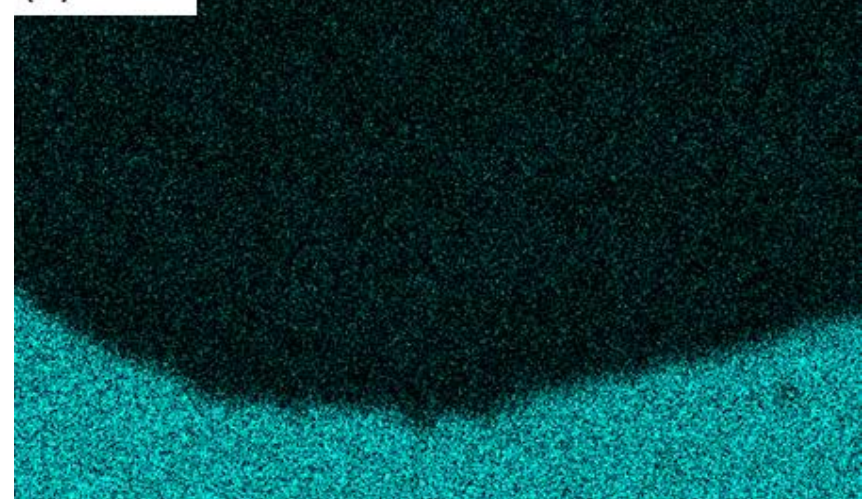

Figure 9 


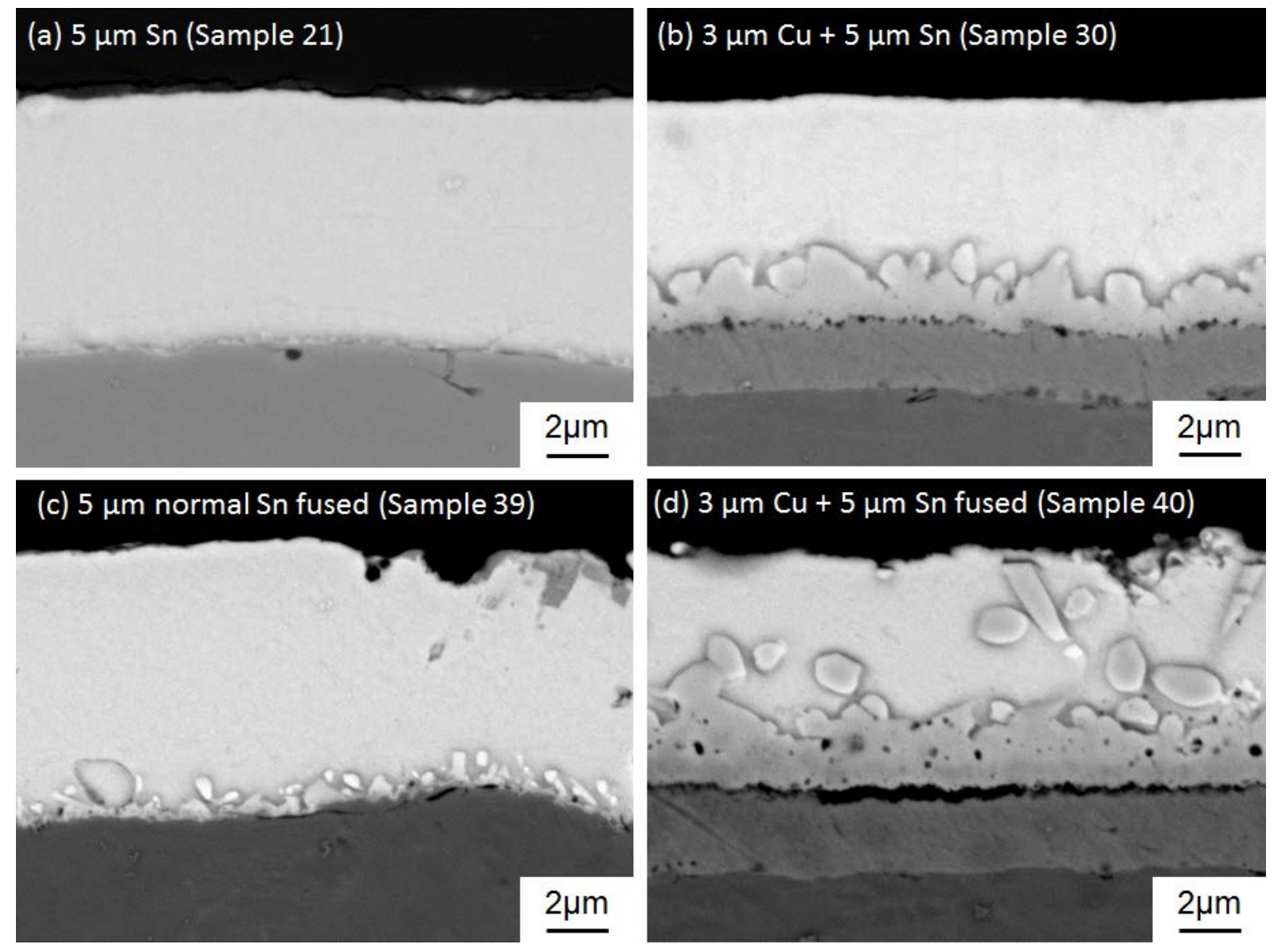

Figure 10 


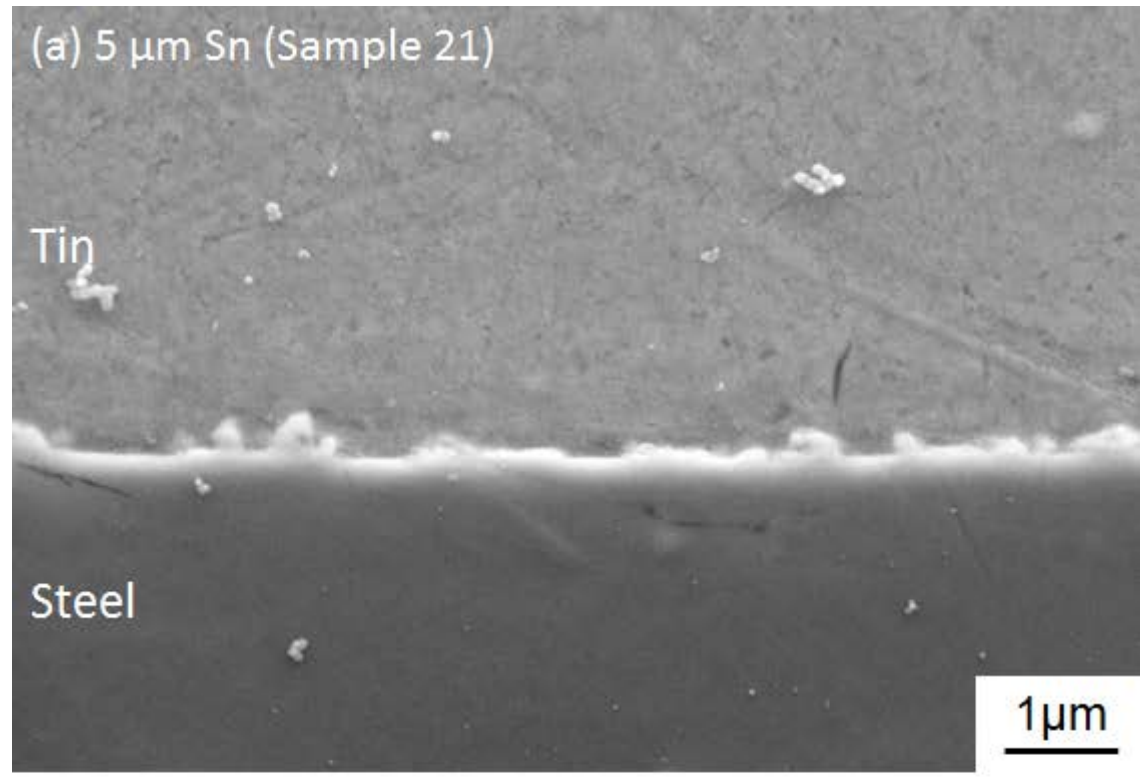

\section{(b) $3 \mu \mathrm{m} \mathrm{Cu}+5 \mu \mathrm{m} \mathrm{Sn} \mathrm{(Sample} \mathrm{30)}$}
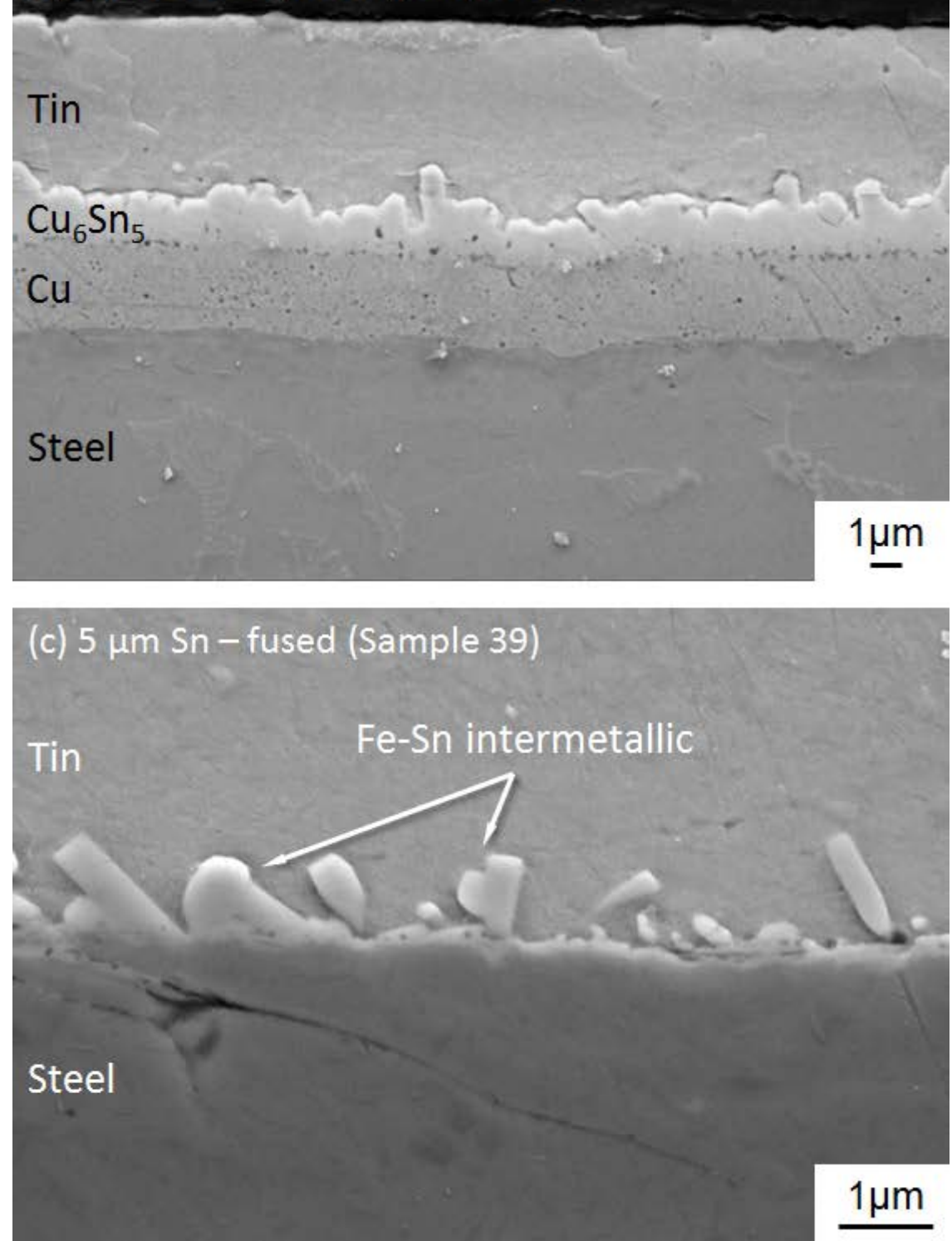

Figure 11 
(a) Secondary electron image

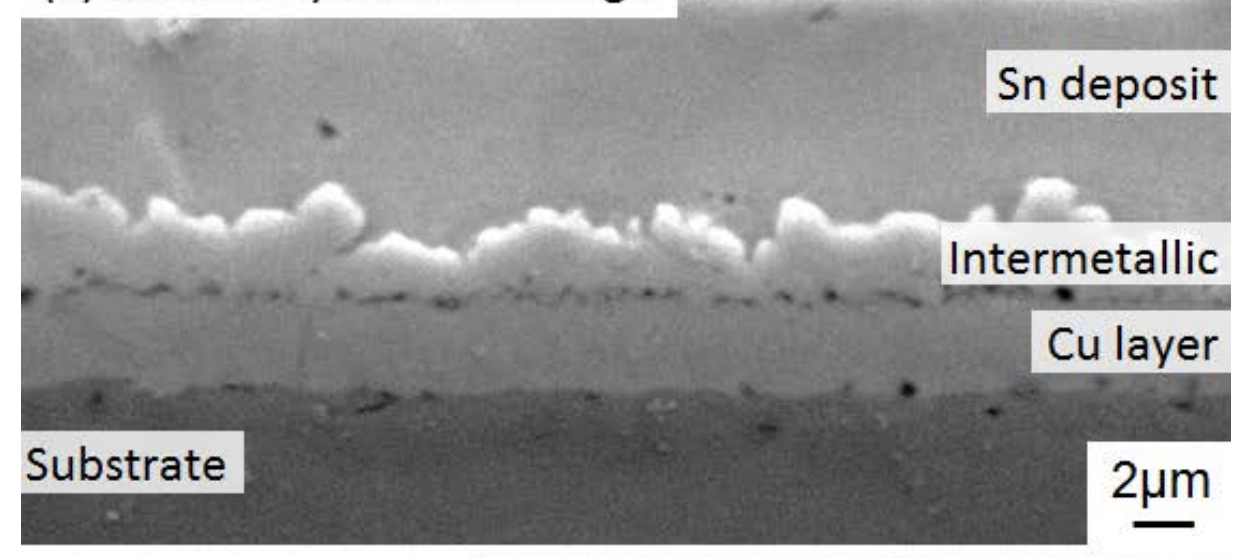

(a) Sn L $\alpha$ x-ray map

(b) Cu K $\alpha$ x-ray map

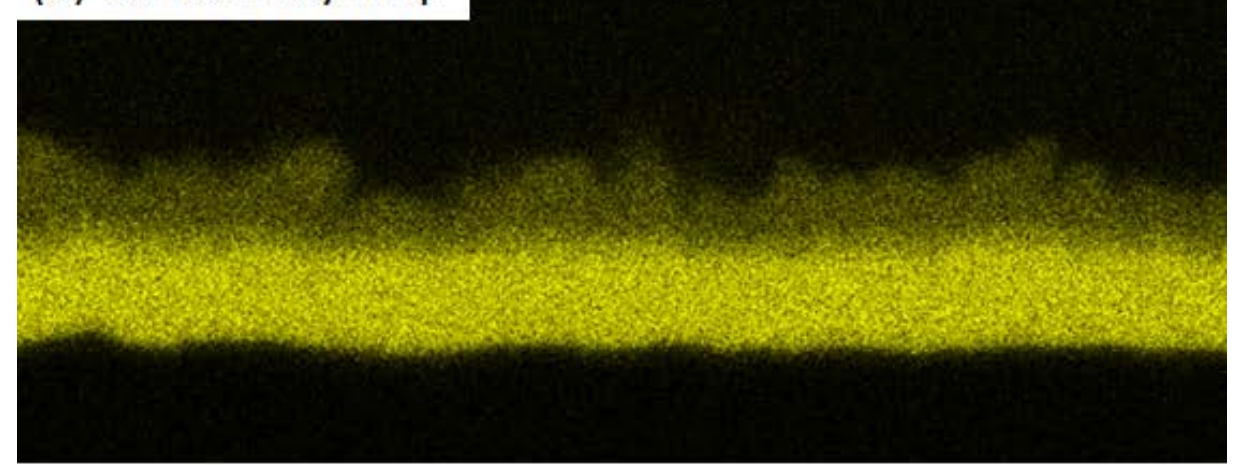

(c) Fe K $\alpha$ x-ray map

Figure 12 


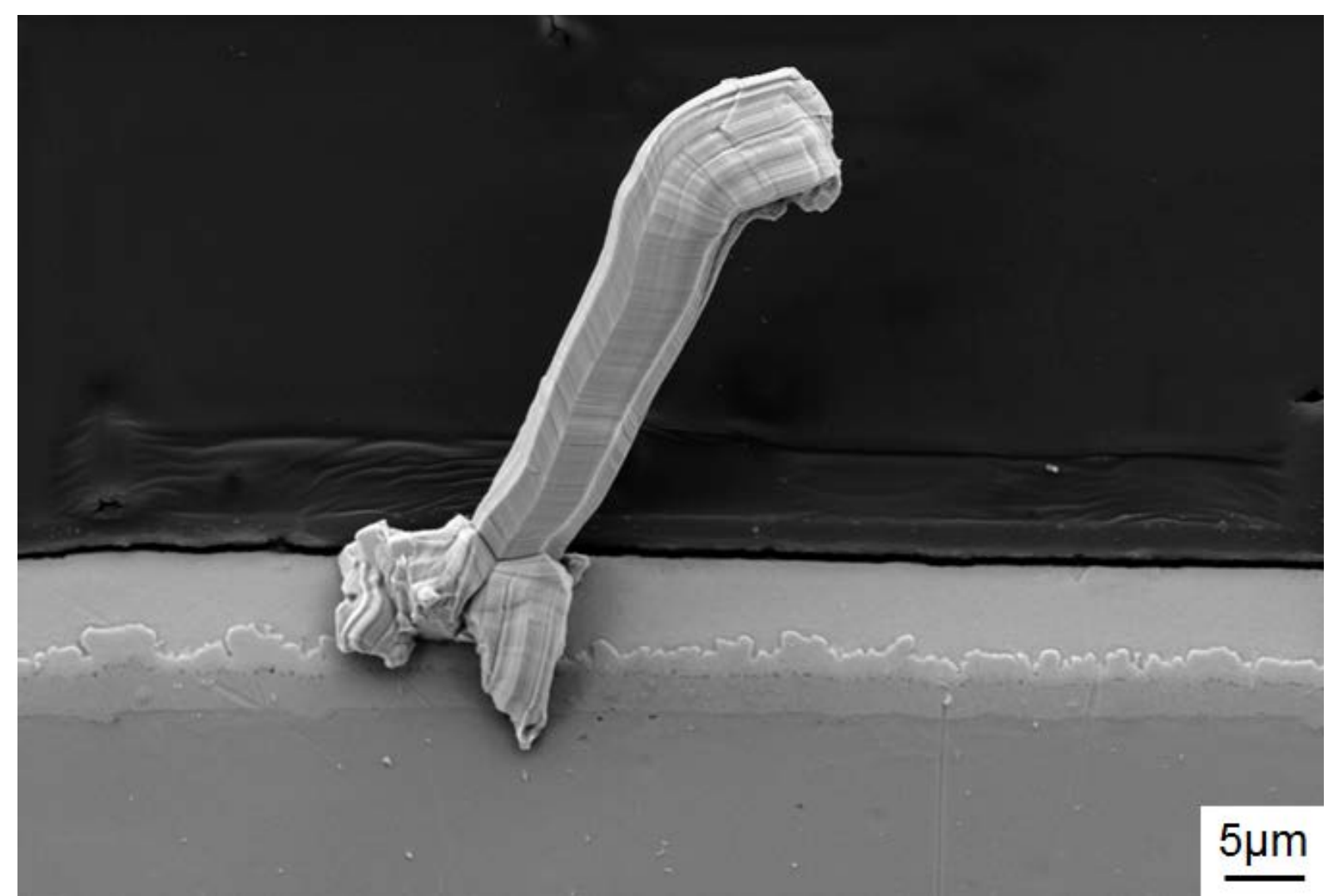

Figure 13 

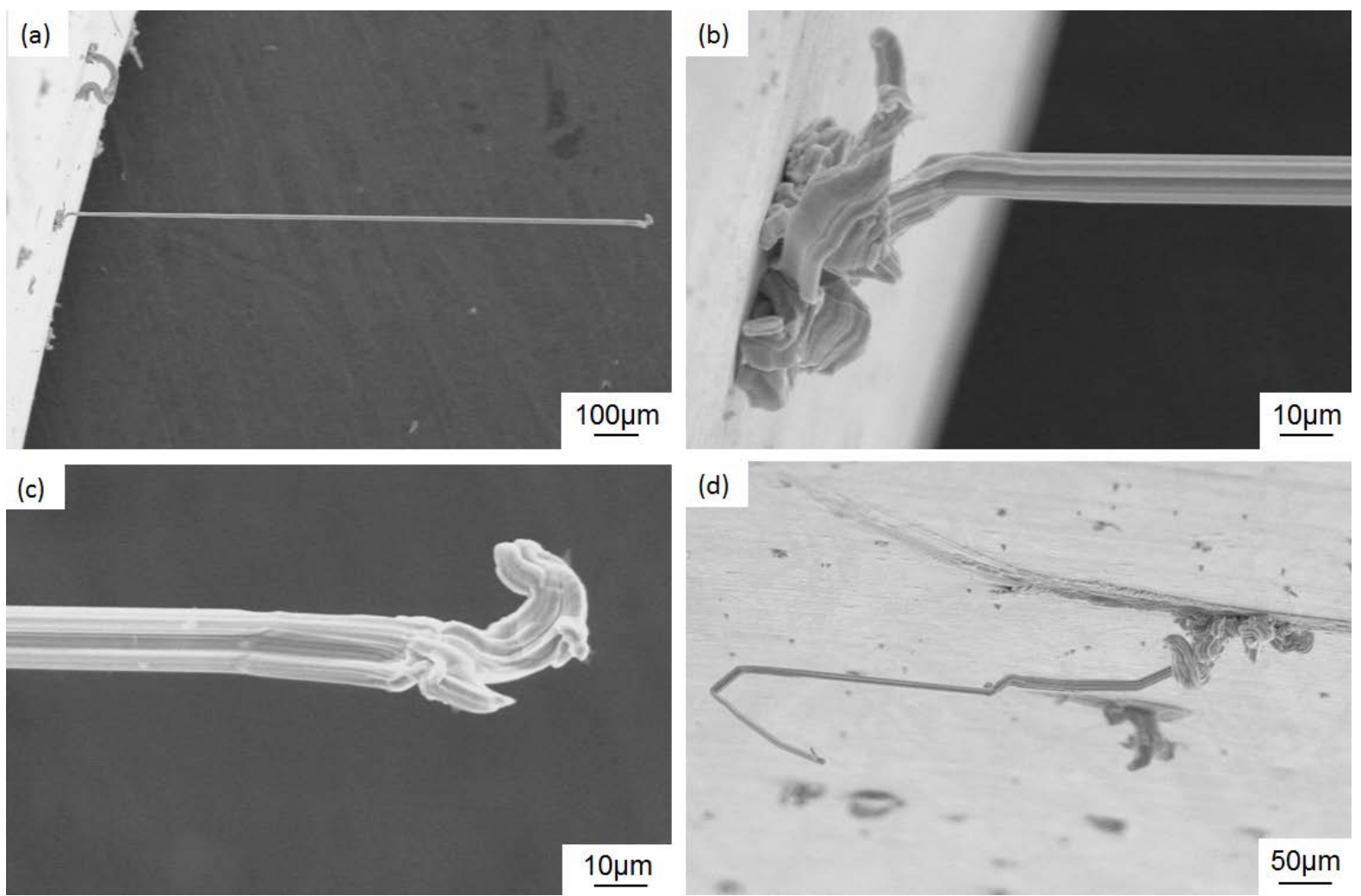

Figure 14 
(a)
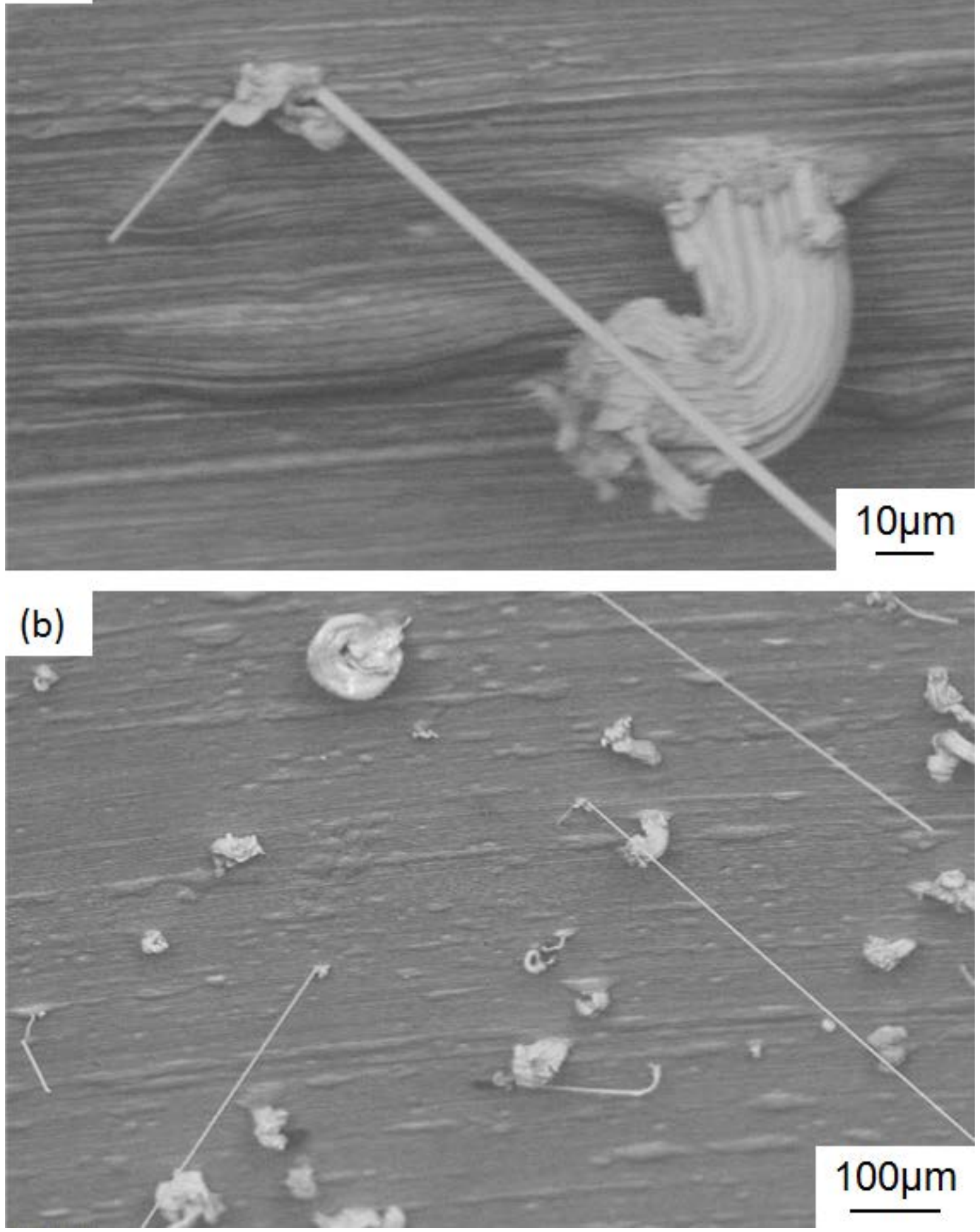

Figure 15 


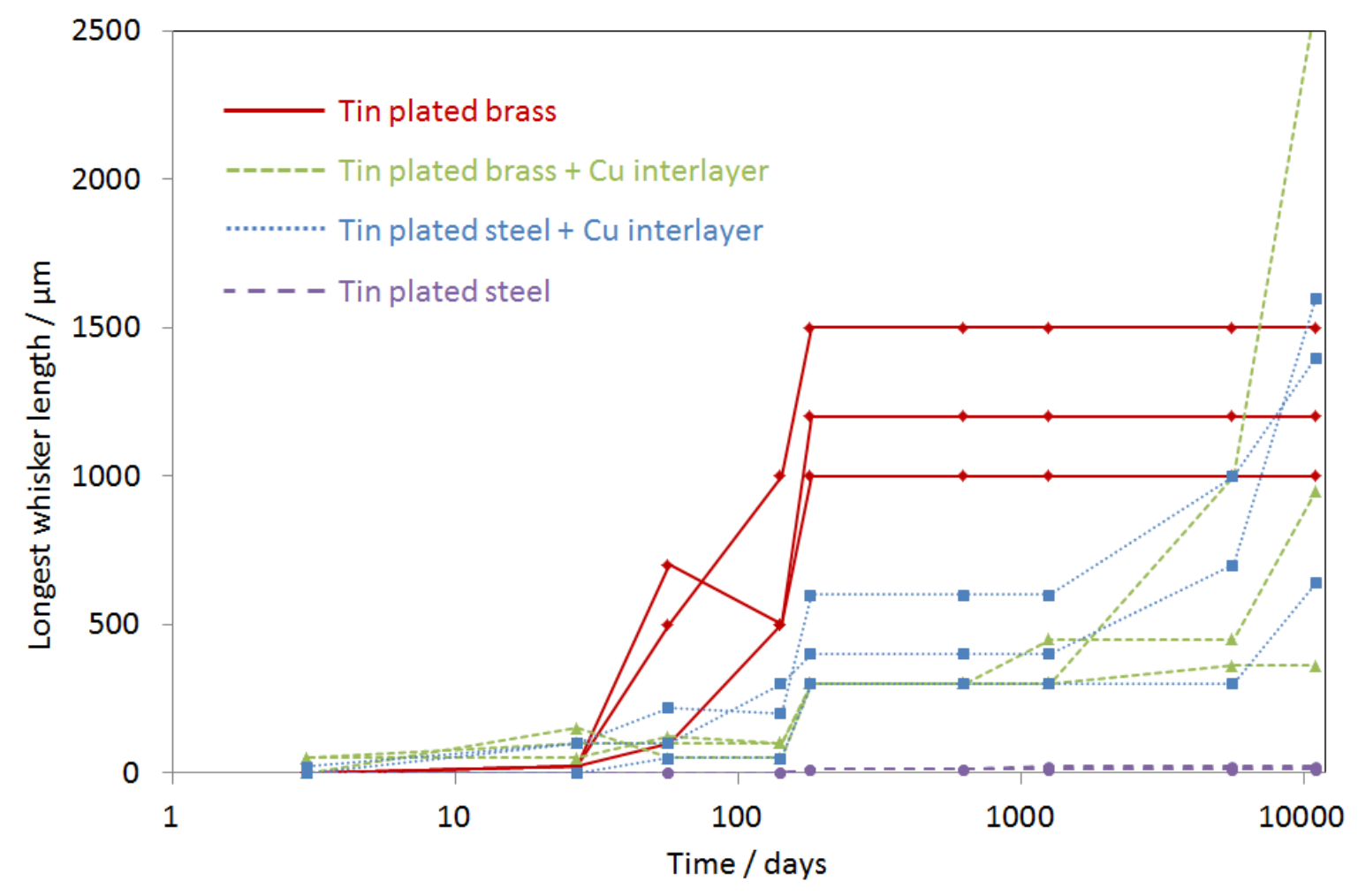

Figure 16 
Table 1

\begin{tabular}{|l|c|c|c|}
\hline & Normal tin & Abnormal tin & $\begin{array}{c}\text { Organically } \\
\text { contaminated tin }\end{array}$ \\
\hline Tin as stannous sulphate (g/l) & 40 & 7.5 & 40 \\
Free sulphuric acid (g/l) & 160 & 160 & 160 \\
Oxymetal brightener no. 4 (cc/l) & 10 & 10 & 10 \\
" no.5 (cc/l) & 4 & 4 & 4 \\
" no.6 (cc/l) & 20 & 20 & 20 \\
Organic flour contamination & none & none & $30^{\circ} \mathrm{C}$ \\
\hline Bath temperature & $20^{\circ} \mathrm{C}$ & $50^{\circ} \mathrm{C}$ & $1.5 \mathrm{~A} / \mathrm{dm}^{2}$ \\
Current density (agitated bath) & $1.5 \mathrm{~A} / \mathrm{dm}^{2}$ & $5 \mathrm{~A} / \mathrm{dm}^{2}$ & \\
\hline
\end{tabular}


Table 2

\begin{tabular}{|c|c|c|c|c|c|c|c|c|c|c|c|c|}
\hline \multirow{2}{*}{$\begin{array}{l}\text { SPECIMEN } \\
\text { NO. }\end{array}$} & \multirow[t]{2}{*}{ TYPE OF TIN } & \multirow{2}{*}{\multicolumn{2}{|c|}{$\begin{array}{l}\text { STRESS } \\
\text { LEVEL }\end{array}$}} & \multicolumn{9}{|c|}{$\begin{array}{c}\text { INSPECTION PERIOD }(\mathrm{d}) \\
\text { LENGTH OF WHISKERS }(\mu \mathrm{m})\end{array}$} \\
\hline & & & & (V) 3 & (S) 27 & (S) 57 & (V)142 & (S)181 & (S) 634 & (S) 1269 & (S)5657 & (S) 11102 \\
\hline \multirow{3}{*}{1} & \multirow{9}{*}{ NORMAL } & & $\mathrm{A}$ & 0 & 20 & 100 & 500 & 1000 & 1000 & 1000 & $1000^{*}$ & $1000^{*}$ \\
\hline & & NONE & B & 0 & 20 & 700 & 500 & 1200 & 1200 & 1200 & 1200 & 1200 \\
\hline & & & $\mathrm{C}$ & 0 & 20 & 500 & 1000 & 1500 & 1500 & 1500 & 1500 & 1500 \\
\hline \multirow{3}{*}{2} & & \multirow{3}{*}{ SLIGHT } & $\mathrm{A}$ & 20 & 0 & 50 & 100 & 1000 & 1000 & 1000 & $1000^{*}$ & $1000 *$ \\
\hline & & & B & 0 & 0 & 0 & 300 & 1000 & 1000 & 1000 & 1000 & 1000 \\
\hline & & & $\mathrm{C}$ & 0 & 0 & 70 & 300 & 1500 & 1500 & 1500 & 1500 & 1500 \\
\hline \multirow{3}{*}{3} & & \multirow{3}{*}{ HIGH } & $\mathrm{A}$ & 0 & 0 & 50 & 100 & 200 & 200 & 200 & 200 & 525 \\
\hline & & & B & 0 & 0 & 20 & 100 & 200 & 600 & 600 & 600 & 600 \\
\hline & & & $\mathrm{C}$ & 0 & 0 & 100 & 100 & 150 & 250 & 250 & 250 & 250 \\
\hline \multirow{3}{*}{4} & \multirow{9}{*}{ ABNORMAL } & \multirow{3}{*}{ NONE } & A & 0 & 0 & 35 & 0 & 50 & 50 & 50 & 50 & 50 \\
\hline & & & B & 0 & 50 & 120 & 100 & 150 & 150 & 150 & 150 & 150 \\
\hline & & & $\mathrm{C}$ & 0 & 0 & 0 & 0 & 10 & 10 & 10 & 10 & 10 \\
\hline \multirow{3}{*}{5} & & \multirow{3}{*}{ SLIGHT } & $\mathrm{A}$ & 0 & 0 & 35 & 30 & 50 & 50 & 50 & 50 & 50 \\
\hline & & & B & 20 & 20 & 100 & 100 & 100 & 100 & 100 & 100 & 100 \\
\hline & & & $\mathrm{C}$ & 0 & 0 & 10 & 0 & 50 & 50 & 50 & 50 & 50 \\
\hline \multirow{3}{*}{6} & & \multirow{3}{*}{ HIGH } & $\mathrm{A}$ & 0 & 0 & 60 & 0 & 200 & 200 & 200 & 200 & 200 \\
\hline & & & B & 0 & 0 & 50 & 100 & 600 & 600 & 600 & 600 & 600 \\
\hline & & & $\mathrm{C}$ & 0 & 0 & 10 & 0 & 10 & 10 & 10 & 30 & 30 \\
\hline \multirow{3}{*}{7} & \multirow{9}{*}{ CONTAMINATED } & \multirow{3}{*}{ NONE } & $\mathrm{A}$ & 0 & 0 & 0 & 0 & 60 & 80 & 80 & 900 & 900 \\
\hline & & & B & 0 & 0 & 0 & 0 & 0 & 0 & 1600 & 2000 & 2000 \\
\hline & & & $\mathrm{C}$ & 0 & 0 & 0 & 0 & 50 & 50 & 200 & 200 & 200 \\
\hline \multirow{3}{*}{8} & & \multirow{3}{*}{ SLIGHT } & $\mathrm{A}$ & 0 & 0 & 0 & 0 & 180 & 180 & 1200 & 2000 & 2000 \\
\hline & & & B & 0 & 0 & 0 & 0 & 100 & 100 & 400 & 2200 & 2400 \\
\hline & & & $\mathrm{C}$ & 0 & 0 & 0 & 0 & 0 & 0 & 400 & 1000 & 1000 \\
\hline \multirow{3}{*}{9} & & \multirow{3}{*}{ HIGH } & $\mathrm{A}$ & 0 & 0 & 0 & 0 & 1000 & 1000 & 1000 & 1500 & 1500 \\
\hline & & & B & 0 & 0 & 10 & 0 & 200 & 200 & 200 & 200 & 200 \\
\hline & & & $\mathrm{C}$ & 0 & 0 & 0 & 0 & 100 & 100 & 100 & 100 & 100 \\
\hline
\end{tabular}


Table 3

\begin{tabular}{|c|c|c|c|c|c|c|c|c|c|c|c|c|}
\hline \multirow{2}{*}{$\begin{array}{l}\text { SPECIMEN } \\
\text { NO. }\end{array}$} & \multirow[t]{2}{*}{ TYPE OF TIN } & \multirow{2}{*}{\multicolumn{2}{|c|}{$\begin{array}{c}\text { STRESS } \\
\text { LEVEL } \\
\text { (Table 3) }\end{array}$}} & \multicolumn{9}{|c|}{$\begin{array}{c}\text { INSPECTION PERIOD }(\mathrm{d}) \\
\text { LENGTH OF WHISKERS }(\mu \mathrm{m})\end{array}$} \\
\hline & & & & (V) 3 & (S) 27 & (S) 57 & (V)142 & (S)181 & (S) 634 & (S) 1269 & (S)5657 & (S) 11102 \\
\hline \multirow{3}{*}{10} & \multirow{9}{*}{ NORMAL } & & $\mathrm{A}$ & 50 & 50 & 120 & 100 & 300 & 300 & 300 & 360 & 360 \\
\hline & & NONE & B & 0 & 150 & 50 & 50 & 300 & 300 & 450 & 450 & 950 \\
\hline & & & $\mathrm{C}$ & 50 & 100 & 100 & 100 & 300 & 300 & 300 & 1000 & 2600 \\
\hline \multirow{3}{*}{11} & & \multirow{3}{*}{ SLIGHT } & $\mathrm{A}$ & 50 & 200 & 500 & 500 & 500 & 500 & 500 & 700 & 1600 \\
\hline & & & B & 50 & 100 & 140 & 200 & 600 & 600 & 600 & 1000 & 1000 \\
\hline & & & $\mathrm{C}$ & 50 & 50 & 60 & 100 & 100 & 100 & 100 & 500 & 500 \\
\hline \multirow{3}{*}{12} & & \multirow{3}{*}{ HIGH } & $\mathrm{A}$ & 0 & 20 & 20 & 0 & 50 & 50 & 450 & 500 & 580 \\
\hline & & & B & 0 & 0 & 10 & 0 & 50 & 50 & 50 & 1000 & 1200 \\
\hline & & & $\mathrm{C}$ & 0 & 0 & 0 & 0 & 50 & 50 & 50 & 500 & 500 \\
\hline \multirow{3}{*}{13} & \multirow{9}{*}{ ABNORMAL } & \multirow{3}{*}{ NONE } & A & 0 & 0 & 100 & 100 & 150 & 200 & 200 & $3500 *$ & $3500^{*}$ \\
\hline & & & B & 0 & 0 & 350 & 100 & 700 & 700 & 700 & 1000 & 1000 \\
\hline & & & $\mathrm{C}$ & 0 & 0 & 10 & 0 & 10 & 10 & 10 & 950 & 950 \\
\hline \multirow{3}{*}{14} & & \multirow{3}{*}{ SLIGHT } & $\mathrm{A}$ & 0 & 0 & 260 & 200 & 280 & 280 & 280 & 1000 & 1000 \\
\hline & & & B & 0 & 0 & 300 & 300 & 300 & 300 & 300 & 2500 & 2500 \\
\hline & & & $\mathrm{C}$ & 0 & 0 & 10 & 0 & 10 & 10 & 10 & 500 & 500 \\
\hline \multirow{3}{*}{15} & & \multirow{3}{*}{ HIGH } & $\mathrm{A}$ & 50 & 300 & 600 & 600 & 1100 & 1100 & 1100 & 2000 & $3900^{*}$ \\
\hline & & & B & 0 & 100 & 400 & 400 & 450 & 450 & 450 & 2500 & 2500 \\
\hline & & & $\mathrm{C}$ & 0 & 100 & 300 & 300 & 600 & 600 & 600 & 600 & 600 \\
\hline \multirow{3}{*}{16} & \multirow{9}{*}{ CONTAMINATED } & \multirow{3}{*}{ NONE } & $\mathrm{A}$ & 0 & 0 & 0 & 0 & 40 & 60 & 100 & 750 & 750 \\
\hline & & & $\mathrm{B}$ & 0 & 0 & 0 & 0 & 40 & 40 & 50 & 250 & 940 \\
\hline & & & $\mathrm{C}$ & 0 & 0 & 0 & 0 & 40 & 40 & 50 & 50 & 50 \\
\hline \multirow{3}{*}{17} & & \multirow{3}{*}{ SLIGHT } & $\mathrm{A}$ & 0 & 0 & 0 & 0 & 200 & 200 & 200 & 1000 & 1200 \\
\hline & & & B & 0 & 0 & 0 & 0 & 40 & 40 & 140 & 1500 & 1500 \\
\hline & & & $\mathrm{C}$ & 0 & 0 & 0 & 0 & 40 & 40 & 40 & 500 & 1200 \\
\hline \multirow{3}{*}{18} & & \multirow{3}{*}{ HIGH } & $\mathrm{A}$ & 0 & 0 & 0 & 0 & 20 & 20 & 20 & 20 & 250 \\
\hline & & & B & 0 & 0 & 10 & 0 & 100 & 100 & 140 & $800^{*}$ & $1200^{*}$ \\
\hline & & & $\mathrm{C}$ & 0 & 0 & 0 & 0 & 40 & 40 & 40 & 150 & 200 \\
\hline
\end{tabular}


Table 4

\begin{tabular}{|c|c|c|c|c|c|c|c|c|c|c|c|c|}
\hline \multirow{2}{*}{$\begin{array}{l}\text { SPECIMEN } \\
\text { NO. }\end{array}$} & \multirow[t]{2}{*}{ TYPE OF TIN } & \multirow{2}{*}{\multicolumn{2}{|c|}{$\begin{array}{l}\text { STRESS } \\
\text { LEVEL }\end{array}$}} & \multicolumn{9}{|c|}{$\begin{array}{l}\text { INSPECTION PERIOD }(\mathrm{d}) \\
\text { LENGTH OF WHISKERS }(\mu \mathrm{m})\end{array}$} \\
\hline & & & & (V)3 & (S) 27 & (S) 57 & (V)142 & (S) 181 & (S)634 & (S)1269 & (S) 5657 & (S) 11102 \\
\hline \multirow{3}{*}{21} & \multirow{9}{*}{ NORMAL } & \multirow{3}{*}{ NONE } & $\mathrm{A}$ & 0 & 0 & 0 & 0 & 10 & 10 & 10 & 10 & 10 \\
\hline & & & $\mathrm{B}$ & 0 & 0 & 0 & 0 & 10 & 10 & 20 & 20 & 20 \\
\hline & & & $\mathrm{C}$ & 0 & 0 & 0 & 0 & 10 & 10 & 10 & 10 & 10 \\
\hline \multirow{3}{*}{22} & & \multirow{3}{*}{ SLIGHT } & $\mathrm{A}$ & 0 & 0 & 0 & 0 & 10 & 10 & 10 & 10 & 15 \\
\hline & & & B & 0 & 0 & 0 & 0 & 10 & 10 & 10 & 10 & 10 \\
\hline & & & $\mathrm{C}$ & 0 & 0 & 0 & 0 & 10 & 10 & 10 & 10 & 10 \\
\hline \multirow{3}{*}{23} & & \multirow{3}{*}{ HIGH } & $\mathrm{A}$ & 0 & 0 & 0 & 0 & 0 & 0 & 10 & 10 & 0 \\
\hline & & & B & 0 & 0 & 0 & 0 & 0 & 0 & 15 & 15 & 0 \\
\hline & & & $\mathrm{C}$ & 0 & 0 & 0 & 0 & 0 & 0 & 0 & 0 & 0 \\
\hline \multirow{3}{*}{24} & \multirow{9}{*}{ ABNORMAL } & \multirow{3}{*}{ NONE } & A & 0 & 0 & 0 & 0 & 0 & 0 & 0 & 0 & 0 \\
\hline & & & B & 0 & 0 & 0 & 0 & 0 & 0 & 0 & 0 & 0 \\
\hline & & & $\mathrm{C}$ & 0 & 0 & 0 & 0 & 0 & 0 & 0 & 0 & 0 \\
\hline \multirow{3}{*}{25} & & \multirow{3}{*}{ SLIGHT } & $\mathrm{A}$ & 0 & 0 & 0 & 0 & 0 & 0 & 0 & 0 & 0 \\
\hline & & & B & 0 & 0 & 0 & 0 & 0 & 0 & 0 & 0 & 0 \\
\hline & & & $\mathrm{C}$ & 0 & 0 & 0 & 0 & 0 & 0 & 0 & 0 & 0 \\
\hline \multirow{3}{*}{26} & & \multirow{3}{*}{ HIGH } & $\mathrm{A}$ & 0 & 0 & 0 & 0 & 0 & 0 & 0 & 0 & 0 \\
\hline & & & B & 0 & 0 & 0 & 0 & 0 & 0 & 0 & 0 & 0 \\
\hline & & & $\mathrm{C}$ & 0 & 0 & 0 & 0 & 0 & 0 & 0 & 0 & 0 \\
\hline \multirow{3}{*}{27} & \multirow{9}{*}{ CONTAMINATED } & \multirow{3}{*}{ NONE } & $\mathrm{A}$ & 0 & 0 & 0 & 0 & 0 & 0 & 0 & 0 & 0 \\
\hline & & & $\mathrm{B}$ & 0 & 0 & 0 & 0 & 0 & 0 & 0 & $0^{*}$ & 0 \\
\hline & & & $\mathrm{C}$ & 0 & 0 & 0 & 0 & 0 & 0 & 0 & 0 & 0 \\
\hline \multirow{3}{*}{28} & & \multirow{3}{*}{ SLIGHT } & $\mathrm{A}$ & 0 & 0 & 0 & 0 & 0 & 0 & 0 & 0 & 0 \\
\hline & & & B & 0 & 0 & 0 & 0 & 0 & 0 & 0 & 0 & 0 \\
\hline & & & $\mathrm{C}$ & 0 & 0 & 0 & 0 & 0 & 0 & 0 & 0 & 0 \\
\hline \multirow{3}{*}{29} & & \multirow{3}{*}{ HIGH } & $\mathrm{A}$ & 0 & 0 & 0 & 0 & 0 & 0 & 0 & 0 & 0 \\
\hline & & & B & 0 & 0 & 0 & 0 & 0 & 0 & 0 & 0 & 0 \\
\hline & & & $\mathrm{C}$ & 0 & 0 & 0 & 0 & 0 & 0 & 0 & 0 & 0 \\
\hline
\end{tabular}


Table 5

\begin{tabular}{|c|c|c|c|c|c|c|c|c|c|c|c|c|}
\hline \multirow{2}{*}{$\begin{array}{l}\text { SPECIMEN } \\
\text { NO. }\end{array}$} & \multirow[t]{2}{*}{ TYPE OF TIN } & \multirow{2}{*}{\multicolumn{2}{|c|}{$\begin{array}{c}\text { STRESS } \\
\text { LEVEL } \\
\text { (Table 3) }\end{array}$}} & \multicolumn{9}{|c|}{$\begin{array}{c}\text { INSPECTION PERIOD }(\mathrm{d}) \\
\text { LENGTH OF WHISKERS }(\mu \mathrm{m})\end{array}$} \\
\hline & & & & (V) 3 & (S) 27 & (S) 57 & (V)142 & (S) 181 & (S) 634 & (S)1269 & (S) 5657 & (S)11102 \\
\hline \multirow[t]{3}{*}{30} & \multirow[t]{9}{*}{ NORMAL } & \multirow[t]{3}{*}{ NONE } & $\mathrm{A}$ & 0 & 100 & 220 & 200 & 600 & 600 & 600 & 1000 & 1400 \\
\hline & & & B & 20 & 100 & 100 & 300 & 400 & 400 & 400 & 700 & 1600 \\
\hline & & & $\mathrm{C}$ & 0 & 0 & 50 & 50 & 300 & 300 & 300 & 300 & 640 \\
\hline \multirow[t]{3}{*}{31} & & \multirow[t]{3}{*}{ SLIGHT } & A & 0 & 50 & 200 & 200 & 250 & 250 & 250 & $1200 *$ & $1200^{*}$ \\
\hline & & & B & 0 & 1000 & 225 & 200 & 300 & 300 & 300 & 500 & 700 \\
\hline & & & $\mathrm{C}$ & 0 & 20 & 100 & 100 & 100 & 100 & 100 & 500 & 500 \\
\hline \multirow[t]{3}{*}{32} & & \multirow[t]{3}{*}{ HIGH } & A & 0 & 200 & 400 & 400 & 500 & 500 & 500 & 1200 & 1950 \\
\hline & & & B & 0 & 100 & 300 & 300 & 400 & 400 & 400 & 1000 & 1000 \\
\hline & & & $\mathrm{C}$ & 0 & 100 & 500 & 500 & 500 & 500 & 500 & 1000 & 1000 \\
\hline \multirow[t]{3}{*}{33} & \multirow[t]{9}{*}{ ABNORMAL } & \multirow[t]{3}{*}{ NONE } & $\mathrm{A}$ & 0 & 100 & 20 & 100 & 600 & 600 & 600 & $4600 *$ & $4600^{*}$ \\
\hline & & & B & 0 & 300 & 20 & 0 & 220 & 220 & 220 & 2000 & 2000 \\
\hline & & & $\mathrm{C}$ & 0 & 0 & 20 & 0 & 100 & 100 & 100 & 2000 & 2000 \\
\hline \multirow[t]{3}{*}{34} & & \multirow[t]{3}{*}{ SLIGHT } & A & 0 & 500 & 800 & 800 & 800 & 800 & 800 & 3500 & 3500 \\
\hline & & & B & 0 & 0 & 50 & 50 & 50 & 50 & 50 & 2000 & 2000 \\
\hline & & & $\mathrm{C}$ & 0 & 50 & 50 & 50 & 50 & 50 & 50 & 2000 & 2000 \\
\hline \multirow[t]{3}{*}{35} & & \multirow[t]{3}{*}{ HIGH } & A & 20 & 500 & 1100 & 1200 & 1200 & 1200 & 1200 & 3000 & 3000 \\
\hline & & & B & 0 & 100 & 425 & 500 & 600 & 600 & 600 & 1000 & 1000 \\
\hline & & & $\mathrm{C}$ & 0 & 100 & 400 & 400 & 300 & 300 & 300 & 2500 & 2500 \\
\hline \multirow[t]{3}{*}{36} & \multirow[t]{9}{*}{ CONTAMINATED } & \multirow[t]{3}{*}{ NONE } & A & 0 & 0 & 0 & 0 & 0 & 50 & 100 & 1000 & 1000 \\
\hline & & & B & 0 & 20 & 40 & 40 & 40 & 70 & 400 & 2000 & 2000 \\
\hline & & & $\mathrm{C}$ & 0 & 0 & 0 & 0 & 0 & 0 & 350 & 1500 & 1500 \\
\hline \multirow[t]{3}{*}{37} & & \multirow[t]{3}{*}{ SLIGHT } & A & 0 & 0 & 50 & 50 & 70 & 70 & 70 & 1500 & 1500 \\
\hline & & & B & 0 & 20 & 50 & 50 & 70 & 70 & 400 & 2000 & 2000 \\
\hline & & & $\mathrm{C}$ & 0 & 0 & 0 & 0 & 70 & 70 & 400 & 1000 & 1000 \\
\hline \multirow[t]{3}{*}{38} & & \multirow[t]{3}{*}{ HIGH } & A & 0 & 0 & 0 & 0 & 0 & 0 & 0 & 1800 & 1800 \\
\hline & & & B & 0 & 20 & 0 & 0 & 60 & 80 & 80 & 500 & 500 \\
\hline & & & $\mathrm{C}$ & 0 & 0 & 0 & 0 & 100 & 100 & 100 & 500 & 500 \\
\hline
\end{tabular}


Table 6

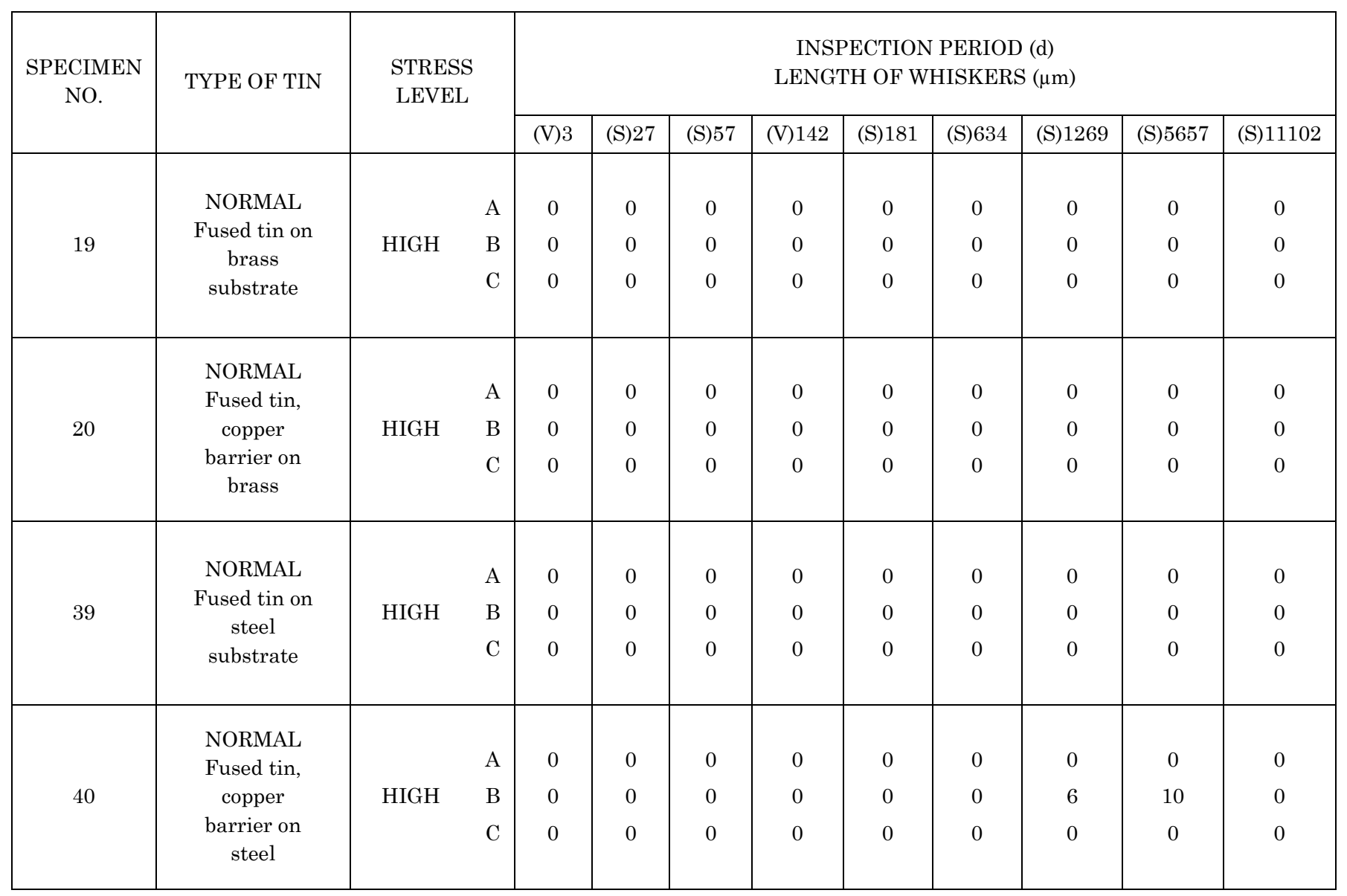

